\title{
Inhibition of Drp1 Ameliorates Synaptic Depression, $A \beta$ Deposition, and Cognitive Impairment in an Alzheimer's Disease Model
}

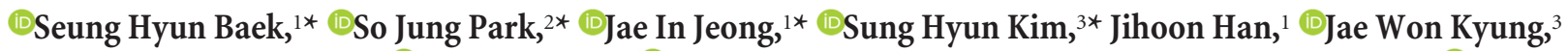 \\ Sang-Ha Baik, ${ }^{1}$ Yuri Choi, ${ }^{1}$ @Bo Youn Choi, ${ }_{1}^{1}$ ○Jin Su Park, ${ }^{1,4}$ Gahee Bahn, ${ }^{1}$ Ji Hyun Shin, ${ }^{2}$ Doo Sin Jo, ${ }^{2}$-Joo-Yong Lee, ${ }^{5}$ \\ Choon-Gon Jang, ${ }^{1}$ Thiruma V. Arumugam, ${ }^{1,6}$ Jongpil Kim, ${ }^{7}$ Jeung-Whan Han, ${ }^{1}$ Jae-Young Koh, ${ }^{5}$ Dong-Hyung Cho, ${ }^{2}$ \\ and Dong-Gyu Jo ${ }^{1,4}$ \\ ${ }^{1}$ School of Pharmacy, Sungkyunkwan University, 16419 Korea, ${ }^{2}$ Graduate School of East-West Medical Science, Kyung Hee University, 17104 Korea, \\ ${ }^{3}$ Department of Physiology, School of Medicine, Kyung Hee University, 02447 Korea, ${ }^{4}$ Department of Health Sciences and Technology, Samsung Advanced \\ Institute of Health Sciences and Technology, Sungkyunkwan University, 06351 Korea, ${ }^{5}$ Department of Neurology, University of Ulsan College of Medicine, \\ Asan Medical Center, 05505 Korea, ${ }^{6}$ Department of Physiology, Yong Loo Lin School Medicine, National University of Singapore, 117593 Singapore, and \\ ${ }^{7}$ Department of Biomedical Engineering (BK21 Plus Team), Dongguk University, Seoul, 100 -715 Korea
}

Excessive mitochondrial fission is a prominent early event and contributes to mitochondrial dysfunction, synaptic failure, and neuronal cell death in the progression of Alzheimer's disease (AD). However, it remains to be determined whether inhibition of excessive mitochondrial fission is beneficial in mammal models of AD. To determine whether dynamin-related protein 1 (Drp1), a key regulator of mitochondrial fragmentation, can be a disease-modifying therapeutic target for $\mathrm{AD}$, we examined the effects of Drp1 inhibitor on mitochondrial and synaptic dysfunctions induced by oligomeric amyloid- $\beta(A \beta)$ in neurons and neuropathology and cognitive functions in $\mathrm{A} \beta$ precursor protein/presenilin 1 double-transgenic $\mathrm{AD}$ mice. Inhibition of Drp1 alleviates mitochondrial fragmentation, loss of mitochondrial membrane potential, reactive oxygen species production, ATP reduction, and synaptic depression in A $\beta$-treated neurons. Furthermore, Drp1 inhibition significantly improves learning and memory and prevents mitochondrial fragmentation, lipid peroxidation, $\mathrm{BACE} 1$ expression, and $\mathrm{A} \beta$ deposition in the brain in the $\mathrm{AD}$ model. These results provide evidence that Drp 1 plays an important role in $\mathrm{A} \beta$-mediated and $\mathrm{AD}$-related neuropathology and in cognitive decline in an $\mathrm{AD}$ animal model. Therefore, inhibiting excessive Drp1mediated mitochondrial fission may be an efficient therapeutic avenue for AD.

Key words: Alzheimer's; amyloid; Drp1; mitochondria; synaptic depression

Significance Statement

Mitochondrial fission relies on the evolutionary conserved dynamin-related protein 1 (Drp1). Drp1 activity and mitochondria fragmentation are significantly elevated in the brains of sporadic Alzheimer's disease (AD) cases. In the present study, we first demonstrated that the inhibition of Drp1 restored amyloid- $\beta(\mathrm{A} \beta)$-mediated mitochondrial dysfunctions and synaptic depression in neurons and significantly reduced lipid peroxidation, BACE1 expression, and A $\beta$ deposition in the brain of AD mice. As a result, memory deficits in $\mathrm{AD}$ mice were rescued by Drp1 inhibition. These results suggest that neuropathology and combined cognitive decline can be attributed to hyperactivation of Drp1 in the pathogenesis of AD. Therefore, inhibitors of excessive mitochondrial fission, such as Drp1 inhibitors, may be a new strategy for AD.

\section{Introduction}

Mitochondria, essential organelles for both life and death, are highly dynamic. They continuously undergo balanced fission and fusion processes, which are termed mitochondrial dynamics (Cho et al., 2010). Mitochondrial dynamics greatly affect mitochondrial functions such as biogenesis, as well as their morphol- 
ogy. Several GTPase proteins, including dynamin-related protein 1 (Drp1), optic dominant atrophy 1 (Opa1), and mitofusin 1/-2 (Mfn1/2), have been identified as regulators of mitochondrial dynamics (Mishra and Chan, 2014). Mitochondrial fission relies on the evolutionary conserved Drp1 protein. Upon stimulation of mitochondrial fission, Drp1 is translocated from the cytosol to the mitochondrial outer membrane and interacts with its receptors, such as mitochondrial fission 1 (Fis1) and mitochondrial fission factor (MFF) to promote the mitochondrial fission process (Lee et al., 2004; Otera et al., 2010). As a regulatory mechanism, various posttranslational modifications such as phosphorylation, nitrosylation, sumoylation, ubiquitination, or GlcNAcylation of Drp1; proteolytic cleavage of Opa1; and ubiquitination or phosphorylation of MFN1/2 have explained the intricate mechanisms of mitochondrial dynamics with different signals (Cho et al., 2010; Cho et al., 2013). Mitochondrial fusion functions as a cell protection mechanism by content mixing, whereas massive mitochondrial fission potentiates cell death (Itoh et al., 2013; Park et al., 2014). Imbalanced mitochondrial dynamics are directly linked to many human diseases including cancer, diabetes, and neurodegenerative diseases (DuBoff et al., 2013; Itoh et al., 2013; Mishra and Chan, 2014). Neurons are particularly dependent on mitochondrial function because of their higher metabolic activity and complex morphology. Because mitochondria are not only the primary producers of reactive oxygen species (ROS), which contribute to mitochondrial dysfunction, but are also pivotal for synaptic development and plasticity, abnormalities in mitochondrial dynamics have been suggested to occur as prominent early events in neurodegenerative diseases such as Alzheimer's disease (AD), Parkinson's disease (PD), Huntington's disease (HD), and amyotrophic lateral sclerosis (ALS) (Itoh et al., 2013; Reddy, 2014).

Membrane-associated oxidative stress, perturbed $\mathrm{Ca}^{2+}$ homeostasis, impaired energy metabolism, apoptosis, and mitochondrial alterations are involved in amyloid- $\beta(\mathrm{A} \beta)$-mediated neuronal degeneration during the $\mathrm{AD}$ process. Mitochondrial dysfunction is an early and prominent feature of $\mathrm{AD}$. In the brains of human $\mathrm{AD}$ cases and $\mathrm{AD}$-like cases, $\mathrm{A} \beta$ plaques are accumulated in mitochondria and may cause structural and functional abnormalities of the organelles (Lustbader et al., 2004; Cha et al., 2012). In addition, mitochondrial abnormalities are found to arise before $\mathrm{A} \beta$ plaque deposition (Xie et al., 2013a, 2013b). Mitochondria from AD brains show fractured cristae, reduced respiratory capacity, and increased fragmentation $(\mathrm{Ba}-$ loyannis, 2006; Cho et al., 2009; Wang et al., 2009a, 2009b). Both the treatment of $\mathrm{A} \beta$ and the overexpression of $\mathrm{A} \beta$ precursor protein (APP) strongly induce synaptic injury in neuronal cells, as well as massive mitochondrial abnormalities (Cho et al., 2009; Tu et al., 2014). Exposure of oligomeric A $\beta$ or excessive NO can lead to S-nitrosylation of Drp1 (SNO-Drp1) at Cys644, which activates Drp1 GTPase activity and results in the accumulation of excessively fragmented mitochondria (Cho et al., 2009). Moreover, Drp1 activity and the level of SNO-Drp1 were significantly

(Grant A120196), and the Basic Science Research Program through the National Research Foundation of Korea (NRF), the Ministry of Education, Science and Technology, Republic of Korea (Grants 2012R1A5A2A28671860 and 2015R1A2A1A01003530).

The authors declare no competing financial interests.

*S.H.B., J.IJ., S.J.P. and S.H.K. contributed equally to this work.

Correspondence should be addressed to either of the following: Dong-Hyung Cho, Graduate School of East-West Medical Science, Kyung Hee University, Yongin, Korea, E-mail: dhcho@khu.ac.kr; or Dong-Gyu Jo, School of Pharmacy, Sungkyunkwan University, Suwon 16419, Korea, E-mail: jodg@skku.edu.

DOI:10.1523/JNEUROSCI.2385-16.2017

Copyright $\odot 2017$ the authors $\quad 0270-6474 / 17 / 375100-12 \$ 15.00 / 0$ elevated in the brains of sporadic AD cases (Cho et al., 2009; Wang et al., 2009a, 2009b; Manczak et al., 2012). Therefore, adjustment of the imbalance in mitochondrial dynamics may have beneficial effects on mitochondrial structure and function and neuronal survival in AD. However, it remains to be determined whether inhibition of excessive mitochondrial fission is beneficial in mammal models of AD. In the present study, we evaluate the effect of the Drp1 inhibitor on mitochondrial dysfunction in $\mathrm{A} \beta$-challenged neurons and AD-like neuropathology in APP/ presenilin 1 (PS1) double-transgenic AD mice.

\section{Materials and Methods}

\section{Animals and treatment}

Hemizygous double-transgenic mice APP/PS1 (APPswe/PSEN1dE9 RRID:MGI:3837130) and age-matched wild-type (WT) littermates were maintained on a C57BL/6J background. All mice were kept on a $12 \mathrm{~h}$ light (lights on at 8:00 A.M.)/12 h dark schedule with ad libitum access to food and water. Six-month-old male APP/PS1 mice were divided into three groups ( $n=7$ in each group): the vehicle administered, $10 \mathrm{mg} / \mathrm{kg}$ mitochondrial division inhibitor (mdivi-1)-treated, and $40 \mathrm{mg} / \mathrm{kg}$ of mdivi1-treated groups. The age-matched littermates were divided into two groups ( $n=5$ in each group: vehicle treated and $40 \mathrm{mg} / \mathrm{kg}$ of mdivi-1treated group). mdivi- 1 was administered by oral injection once a day for a month. The Morris water maze (MWM) test began on day 31 of treatment with daily training sessions and lasted until day 34 . We conducted the probe test day 35 to assess long-term memory retention. We trained mice for passive avoidance test on day 37 and the test was done on day 38 . Animals were anesthetized with zoletil and perfused with PBS $(0.9 \%$ $\mathrm{NaCl}$ ) and then killed on day 40. Brain tissue was carefully dissected and some of brains were collected in liquid nitrogen and stored at $-80^{\circ} \mathrm{C}$. The other brains were fixed in $4 \%$ paraformaldehyde for $24 \mathrm{~h}$ and then incubated in $30 \%$ sucrose at $4^{\circ} \mathrm{C}$ for immunohistochemistry. This study was reviewed and approved by the Institutional Animal Care and Use Committee of Sungkyunkwan University. All efforts were made to minimize animal suffering and a minimal number of animals was used. We adhered to ARRIVE (Animal Research: Reporting of In Vivo Experiments) guidelines at all steps of the experiments.

\section{MWM test}

The MWM is a white circular pool $(120 \mathrm{~cm}$ in diameter and $35 \mathrm{~cm}$ in height) with a featureless inner surface. The circular pool was filled with water and nontoxic, water-soluble white dye $\left(22 \pm 1^{\circ} \mathrm{C}\right)$. The pool was divided into four quadrants of equal area. A white platform $(8 \mathrm{~cm}$ in diameter and $10 \mathrm{~cm}$ in height) was centered in 1 of the 4 quadrants of the pool and submerged $1 \mathrm{~cm}$ below the water surface so that it was invisible at water level. The pool was located in a test room, which contained various prominent visual cues. The location of each swimming mouse, from the start position to the platform, was monitored by a video tracking system (Ethovision system; Noldus). The experimental group had no water maze pretraining. In the water maze experiments, the day before the experiment was dedicated to swimming training for $120 \mathrm{~s}$ in the absence of the platform. The mice were then given 2 trial sessions each day for 4 consecutive days, with an intertrial interval of $15 \mathrm{~min}$, the escape latencies were recorded, and the average of 2 trials was determined. If the mouse did not locate the platform within $120 \mathrm{~s}$, it was permitted to remain on it for $10 \mathrm{~s}$ and then removed from the pool by the experimenter. On the fifth day of MWM test, the probe test was conducted for $60 \mathrm{~s}$ without the platform in the pool. The latency to reach the former location of the platform, the time spent traveled in the target quadrant, and the frequency of original platform crossings were measured. The point of entry of the mouse into the pool and the location of the platform for escape remained unchanged between trials 1 and 2, but was changed each day thereafter. Behavioral data were analyzed statistically using repeated-measures and multivariate analysis with LSD post hoc test.

\section{Passive avoidance test}

Experiments were conducted in a two-compartment apparatus (a bright compartment and a dark compartment divided by a guillotine door). On 
A

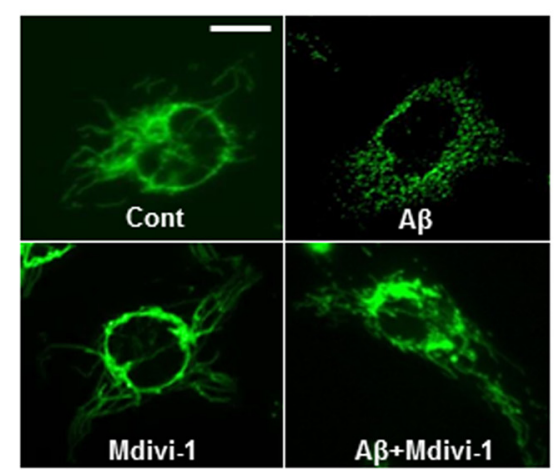

D

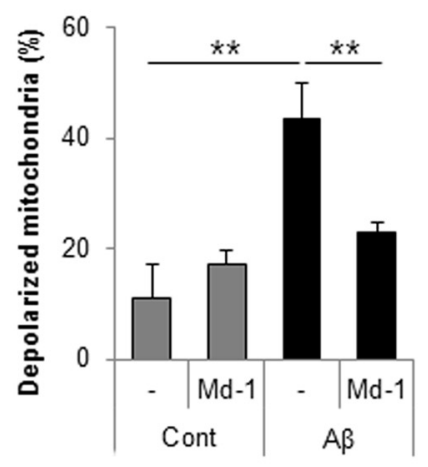

B

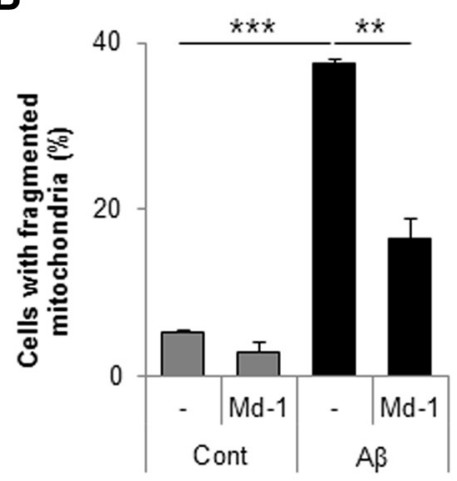

E

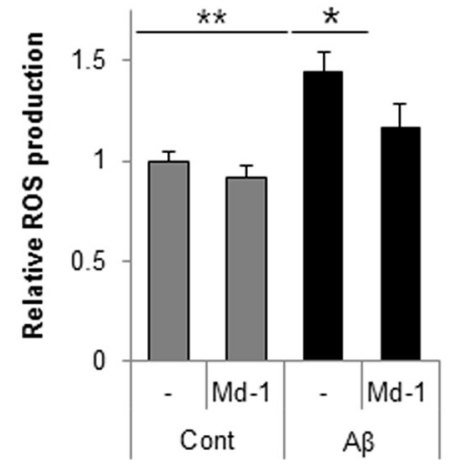

C

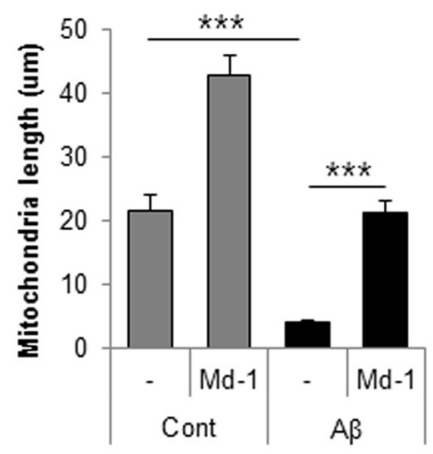

$\mathbf{F}$

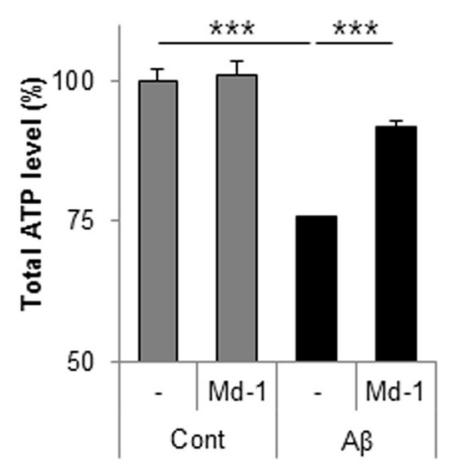

Figure 1. mdivi-1 inhibits A $\beta$-mediated mitochondrial fragmentation and dysfunction in neuroblastoma cells. $\boldsymbol{A}$ - $\boldsymbol{C}$, SK-N-MC cells stably expressing mito-YFP (SK/mito-YFP) were treated with $A \beta(1-42)$ oligomer $(10 \mu \mathrm{m})$ in the presence or absence of mdivi-1 $(25 \mu \mathrm{m})$ for $4 \mathrm{~h}$. Then, the cells were imaged using a fluorescence microscope $(\boldsymbol{A})$, cells with fragmented mitochondria were counted $(\boldsymbol{B})$, and mitochondrial length was measured $(\boldsymbol{C})$. $\boldsymbol{D}-\boldsymbol{F}$, SK-N-MC cells were treated with $A \beta(10 \mu \mathrm{m})$ in the presence or absence of mdivi- 1 ( $25 \mu \mathrm{m})$ for $8 \mathrm{~h}$. $\boldsymbol{D}$, Then, the alteration of mitochondrial membrane potential was monitored by the Mito-Probe JC-1 assay. $\boldsymbol{E}$, Intracellular ROS level was measured by a $\mathrm{H}_{2}$ DCF-DA fluorescence ROS detection assay. $\boldsymbol{F}$, Next, the cellular total ATP level was examined by an ATP bioluminescence detection assay. Scale bar, $10 \mu \mathrm{m}$. Data are presented as the means \pm SEM ( $n=4)$. One-way ANOVA followed by Turkey post hoc comparisons tests were performed in all statistical analyses $\left({ }^{*} p<0.05,{ }^{* *} p<0.01,{ }^{* * *} p<0.001\right)$.

training day, the mouse was placed in the bright compartment facing away from the dark compartment, allowed to explore for $30 \mathrm{~s}$, and then the guillotine door was lifted. When the mouse entered the dark compartment with all four paws, the guillotine door was closed and the latency to enter was recorded (from the time that the door was lifted). Three seconds after the door was closed, a foot shock $(0.5 \mathrm{~mA}, 2 \mathrm{~s})$ was delivered. Thirty seconds after the foot shock, the mouse was removed. On test day ( $24 \mathrm{~h}$ after training), the mouse was placed in the bright compartment facing away from the dark compartment. After $5 \mathrm{~s}$, the guillotine door was lifted. When the mouse entered the dark compartment with all four paws, the guillotine door was closed and the latency to enter the dark compartment was recorded (test time was a total of $5 \mathrm{~min}$ until the mouse entered the dark room). After the test, the mouse was removed and returned to the home cage.

\section{Cell culture, experimental treatments, and measurement of mitochondrial length}

SK-N-MC (catalog \#HTB-10, RRID:CVCL_0530) and SH-SY5Y (catalog \#CRL-2266, RRID:CVCL_0019) neuroblastoma cells were obtained from the American Type Culture Collection. Cells were cultured at $37^{\circ} \mathrm{C}$ in a $5 \% \mathrm{CO}_{2}$ incubator and maintained in DMEM containing $10 \%$ fetal bovine serum (FBS) and $1 \%$ penicillin/streptomycin (Invitrogen). To generate stable cell line, SK-N-MC cells were transfected with pmito-YFP (SK/mito-YFP) using Lipofectamine 2000 according to the manufacturer's protocol (Invitrogen). Stable transfectants were selected by growth in selection medium containing G418 $(1 \mathrm{mg} / \mathrm{ml})$ for $10 \mathrm{~d}$. After single-cell dropping, the stable clones were selected under a fluorescence microscope and confirmed by Western blot analysis. Mean mitochondrial length in SK/mito-YFP cells was determined by measuring at least 20 individual mitochondria from images of multiple cells obtained by con- focal microscopy. A YFP-fused MitoTracker plasmid (pmito-YFP) was described previously (Park et al., 2014). A $\beta$ (1-42) peptide was purchased from the American Peptide Company. A MitoTracker probe and DAPI dye were purchased from Invitrogen.

\section{Preparation of $A \beta$ oligomers}

A $\beta$ (1-42) peptides lyophilized from 1,1,1,3,3,3,-hexafluoroisopropanol were solubilized in DMSO ( $2 \mathrm{~mm})$ and then in F-12 medium to a final concentration of $125 \mu \mathrm{M}$. A $\beta$ (1-42) peptide freshly diluted was used as an $\mathrm{A} \beta$ monomer. $\mathrm{A} \beta(1-42)$ peptides incubated at $4^{\circ} \mathrm{C}$ for $24 \mathrm{~h}$ was centrifuged at $12,000 \times g$ for $10 \mathrm{~min}$ and the resulting supernatant was used as an $\mathrm{A} \beta$ oligomer. Prepared oligomeric $\mathrm{A} \beta$ was characterized by SDS-PAGE.

\section{Intracellular and mitochondrial ROS measurements}

Intracellular ROS levels were measured using a fluorescent dye, $2^{\prime}, 7^{\prime}$ dichlorofluorescein diacetate $\left(\mathrm{H}_{2} \mathrm{DCF}-\mathrm{DA}\right)$ (Invitrogen), which was converted to the highly fluorescent $2^{\prime}, 7^{\prime}$-dichlorofluorescein (DCF) in the presence of oxidant. Briefly, cells were plated in 96-well plates. With or without further treatment of $A \beta$ for $24 \mathrm{~h}$, the cells were incubated with $\mathrm{H}_{2}$ DCF-DA $(5 \mu \mathrm{M})$ in serum-free medium for $30 \mathrm{~min}$ (excitation/emission wavelength 358/485; Victor X3; PerkinElmer). Relative intracellular ROS ratio was presented as the change in fluorescence of drug-treated samples compared with that of control samples. The level of mitochondrial superoxide anion was detected by using MitoSox-red (Invitrogen, M36008) as instructed by the manufacturer. To detect ROS in mitochondria, we pretreated mdivi-1 $(25 \mu \mathrm{M})$ for $4 \mathrm{~h}$ and continuously treated $\mathrm{A} \beta$ $(5 \mu \mathrm{M})$ for $4 \mathrm{~h}$. After that time, we exchanged media and rat primary cortical neuron cells were incubated with $2.5 \mu \mathrm{M}$ MitoSox-red for $20 \mathrm{~min}$ 
A

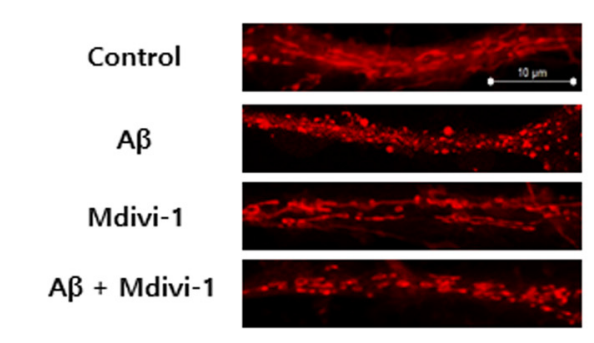

B

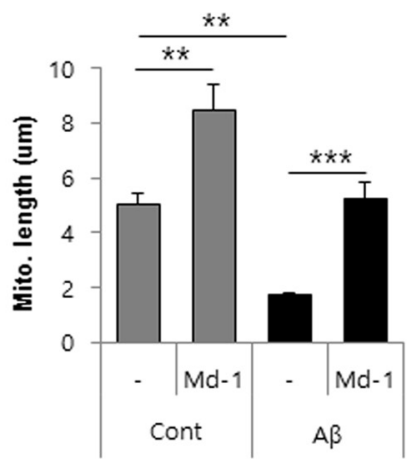

$\mathbf{E}$
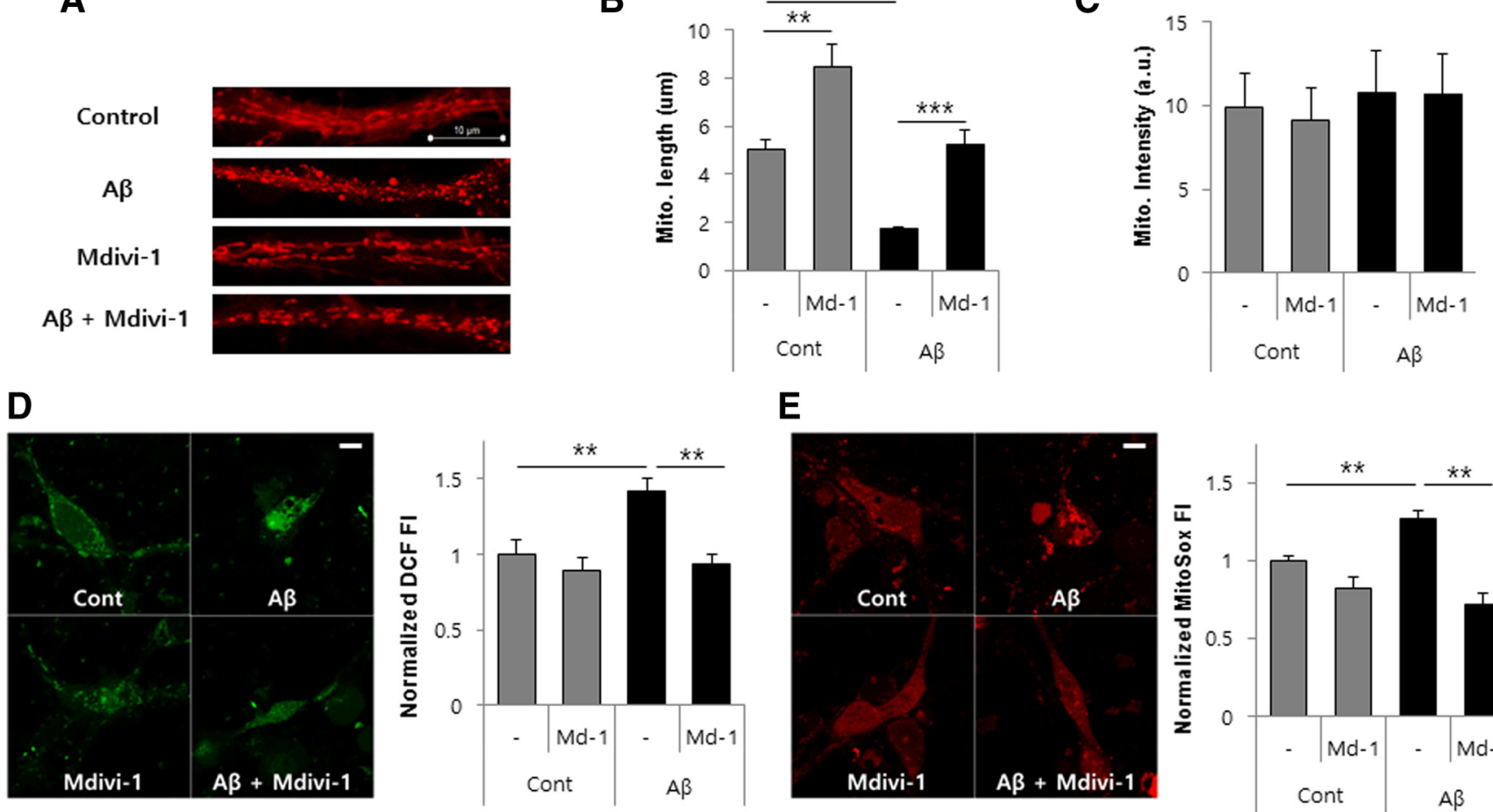

D

Figure 2. mdivi-1 inhibits mitochondrial fragmentation and ROS production in $A \beta$-treated primary hippocampal neurons. $A-D$, Primary hippocampal neurons treated with $A \beta$ (1-42) oligomer $(5 \mu \mathrm{m})$ in the presence or absence of mdivi-1 $(25 \mu \mathrm{m})$ for $6 \mathrm{~h}$ and then the mitochondria were stained with a selective mitochondrial probe (100 $\mathrm{nm}$ ) (MitoTracker). Mitochondria were imaged by a confocal microscopy $(\boldsymbol{A})$ and the length $(\boldsymbol{B})$ and intensity $(\boldsymbol{C})$ of the mitochondria were measured in confocal 3D images. Intracellular ROS accumulation of $A \beta$-treated hippocampal neurons was assayed using $\mathrm{H}_{2} \mathrm{DCF}-\mathrm{DA}$ fluorescent dye (D). $\boldsymbol{E}$, Mitochondrial ROS induction by $\mathrm{A} \beta$ was detected by MitoSox Red staining in hippocampal neurons. Scale bar, $20 \mu \mathrm{m}$. Data are presented as the means $\pm \operatorname{SEM}(n=4)$. One-way ANOVA followed by Turkey post hoc comparisons tests were performed in all statistical analyses $\left({ }^{*} p<0.05,{ }^{* *} p<0.01,{ }^{* * *} p<0.001\right)$.

and then exchanged media. Fluorescence-stained cells were analyzed by confocal microscopy.

Measurement of mitochondria membrane potential and ATP level Mitochondrial membrane potential was examined with a unique fluorescent cationic dye, JC-1 (5,5',6,6'-tetrachloro-1,1',3,3' -tetraethylbenzimidazolylcarbocyanine iodide; BD Biosciences), which detects loss of signal of mitochondrial membrane potential. The depolarized mitochondria were measured using a NucleoCounter NC-3000 apparatus (Chemometec). Cellular total ATP level was detected with an ATP bioluminescence detection kit (Promega) according to the manufacturer's protocol.

\section{Primary neuronal cell culture}

Primary dissociated cell cultures of hippocampal and cortical neurons were prepared from 18-d-old rat embryos as described previously (Gwon et al., 2012). Briefly, hippocampus and cortex were removed from rat embryos, stripped of blood vessels and meninges, minced, and treated with trypsin (HyClone) for $15 \mathrm{~min}$ at $37^{\circ} \mathrm{C}$, followed by gentle trituration with a pipette. The dissociated cells were plated at a density of cells on poly-L-lysine-coated cover slides. Cells were maintained in DMEM (Hyclone) supplemented with $10 \%$ heat-inactivated (v/v) FBS and $1 \%(\mathrm{v} / \mathrm{v})$ penicillin/streptomycin (Invitrogen). Twenty-four hours after plating, the culture medium was replaced with the same volume of Neurobasal-A medium (Invitrogen) containing 2\% (v/v) B27 supplement (Invitrogen). Half of the medium was replaced every other day. After $14 \mathrm{~d}$ in culture, the primary hippocampal neurons were identified using immunofluorescence staining with antibodies and dyes. The cultured neurons were randomly divided into experimental groups and used for in vitro experiments.

\section{Western blot and RT-PCR}

Antibodies. Antibodies used were as follows: anti-BACE1 1:2000 (Cell Signaling Technology catalog \#5606S RRID:AB_1903900), anti-fulllength APP 1:5000 and C-terminal form 1:2000 (CTF- $\beta$ ) (Sigma-Aldrich catalog \#A8717 RRID:AB_258409), and anti- $\beta$-Actin 1:5000 (SigmaAldrich catalog \#A5441 RRID:AB_476744).

Primers. Primers used were as follows: mouse Bace1 forward 5-TCC TTCCGCATCACCATC-3, reverse 5-ACAGTCGTCTTGGGACGTG-3; mouse Bace1 forward 5-TGCATCGCTACTA CCAGAGG-3, reverse 5-CATGAGGGATGCTCACCAG-3; and mouse $\beta$-actin forward 5-GCT GTGCTATGTTGCTCTA-3, reverse 5-CTCGTTGCCAATAGTGATGA-3.

\section{Immunocytochemistry and immunohistochemistry}

Immunocytochemical and immunohistochemical analyses were performed as described previously (Baik et al., 2015). Primary neurons were seeded on coverslips coated with poly-D-lysine for $24 \mathrm{~h}$. Cells were then incubated at $37^{\circ} \mathrm{C}$ with $5 \mu \mathrm{M} \mathrm{A} \beta(1-42)$ oligomer for $6 \mathrm{~h}$ with or without pretreatment of mdivi-1 for $4 \mathrm{~h}$. After cells were then incubated at $37^{\circ} \mathrm{C}$ with $100 \mathrm{~nm}$ MitoTracker Red and $5 \mu \mathrm{M} \mathrm{H}_{2}$ DCF-DA for $30 \mathrm{~min}$, washed with PBS, and fixed with $4 \%$ paraformaldehyde for $10 \mathrm{~min}$. Cells were washed in PBS and mounted on glass slide in mounting medium (Vector Laboratories) with DAPI (AbD Setotec). For immunohistochemistry, brains of mice were fixed by perfusion with $4 \%$ paraformaldehyde (PFA) in PBS and then in PFA $+30 \%$ sucrose for $48 \mathrm{~h}$ at $4^{\circ} \mathrm{C}$. Fixed brains were cut on a microtome (CM3050S; Leica Microsystems) in $45-\mu \mathrm{m}$-thick slices and tissue sections were collected in a cold cryoprotectant solution ( $80 \mathrm{~mm} \mathrm{~K}_{2} \mathrm{HPO}_{4}, 20 \mathrm{~mm} \mathrm{KH} \mathrm{PO}_{4}, 154 \mathrm{~mm} \mathrm{NaCl}, 0.3 \mathrm{~g} / \mathrm{ml}$ sucrose, 0.01 $\mathrm{g} / \mathrm{ml}$ polyvinylpyrrolidone, and $30 \% \mathrm{v} / \mathrm{v}$ ethylene glycol). We prepared brain frozen section slices that were washed 5 times for 3 min in 1 PBS and blocked in 5\% FBS with $0.1 \%$ Triton X-100 for $1 \mathrm{~h}$, followed by overnight incubation with primary antibody in blocking solution at $4^{\circ} \mathrm{C}$. The brain sections were immunostained with primary antibodies against HNE-Michael adducts (Millipore catalog \#393207-100UL RRID: AB_566310) and A $\beta$ (6E10; Covance Research Products catalog \#SIG39300-1000; RRID:AB_10175637). MitoTracker red (100 nM dye diluted in PBS; Invitrogen) staining was performed after antibody staining. After the primary antibody-binding step, brain slices were washed 5 times in 
A
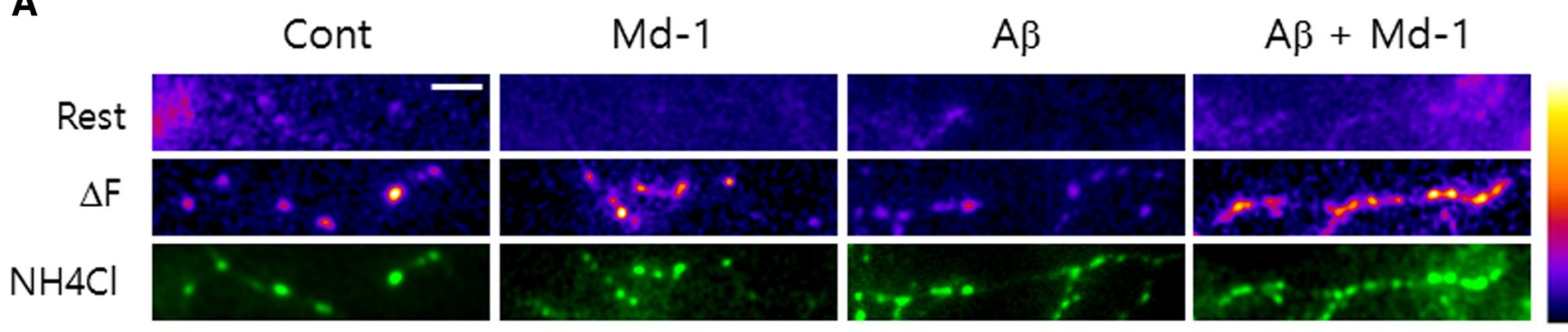

B

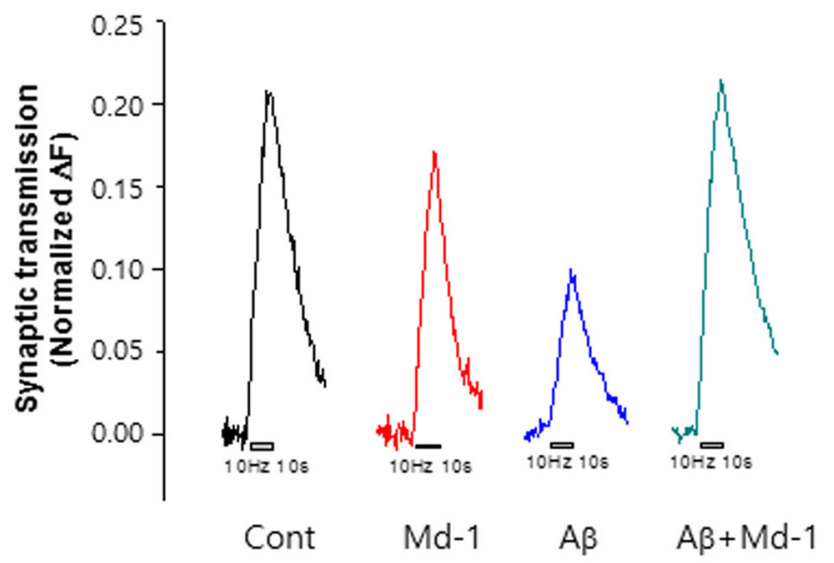

C

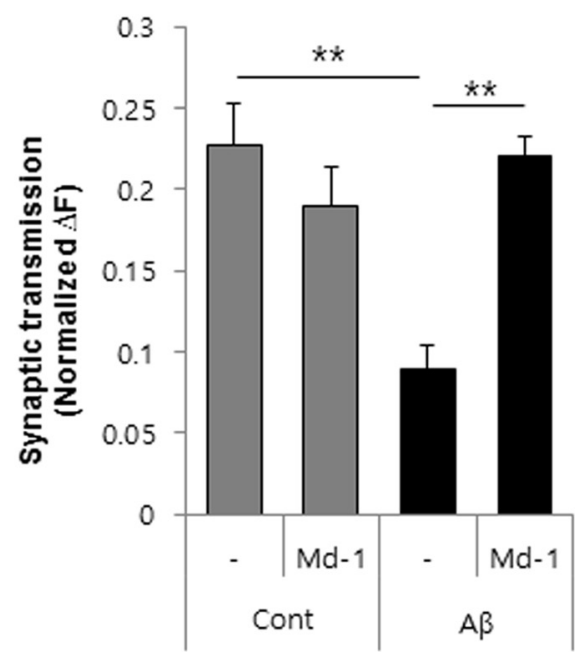

Figure 3. mdivi-1 suppresses synaptic depression in A $\beta$-treated primary cultured hippocampal neurons. $A$, Representative images of primary hippocampal neurons transfected with vG-pH in each condition. Top images are the resting condition, middle images are $\Delta F$ images of the 100 action potential. Bottom is the visualization of all synaptic boutons by applying $\mathrm{NH}_{4} \mathrm{Cl}$. $B$, Representative traces of synaptic vesicle exocytosis stimulated by 100 action potential from control, mdivi-1-treated, $A \beta$-treated, and mdivi- $1+A \beta$-treated neurons. Neurons transfected with VG-pH were stimulated at $10 \mathrm{~Hz} 10 \mathrm{~s}$ with or without mdivi- 1 and $\mathrm{A} \beta$. Intensities were normalized to the peak $\mathrm{NH}_{4} \mathrm{Cl}$ response. $C$, Mean values of amplitudes of 100 action potential response in control $(n=9$ cells), mdivi-1-treated $(n=8)$, A $\beta$-treated $(n=15)$, and mdivi-1 +A $\beta$-treated $(n=12)$ neurons. Scale bar, $5 \mu \mathrm{m}$. Data represent means \pm SEM. One-way ANOVA followed by Turkey post hoc comparisons tests were performed in all statistical analyses $\left({ }^{* *} p<0.001\right)$.

$1 \times$ PBS for 3 min and incubated with anti-mouse Alexa Fluor 488 or anti-rabbit Alexa Fluor 594 for 2 h, followed by washing 3 times with $1 \times$ PBS for $3 \mathrm{~min}$, and then brain slices were mounted with DAPI plus mounting medium on glass slides. All photographs were taken with a confocal microscope (Carl Zeiss, LSM700 RRID:SCR_013672) with a $40 \times$ objective.

Presynaptic functional assay ( $v$ Glut-pHluorin assay)

pHluorin-tagged synaptic vesicle proteins have proven to be a useful probe for examining the kinetics of endocytosis at nerve terminals (Sankaranarayanan and Ryan, 2000; Sankaranarayanan et al., 2000; Granseth et al., 2006; Kim et al., 2009). Hippocampal CA3-CA1 regions were dissected from postnatal 0- to 1-d-old Sprague-Dawley rats, dissociated, and plated onto poly-ornithine-coated glass for 14-20 d. Coverslips were mounted in a stimulation chamber on a custom-built laser illuminated fluorescence microscope. Cells were perfused with Tyrode's solution at low flow rate $(100-200 \mu \mathrm{l} / \mathrm{min})$. Cells were illuminated using a $488 \mathrm{~nm}$ OBIS laser (Coherent Technologies) shuttered by synchronizing the TTL ON/OFF signal from the camera. Fluorescence excitation and collection was through a $40 \times / 1.3$ numerical aperture Fluar Zeiss objective using 515-560 nm emission and $510 \mathrm{~nm}$ dichroic filters (Chroma). Images were acquired with an iXon ultra 897 (Andor) back-illuminated electronmultiplying charge coupled device camera. Action potentials were evoked by passing $1 \mathrm{~ms}$ current pulses via platinum-iridium electrodes from an isolated current stimulator (World Precision Instruments).

\section{Statistics}

Data were obtained from at least three independent experiments and are presented as means \pm SEM. Statistical analyses were performed using
GraphPad Prism 5 software. Statistical significance was determined by Student's $t$-test for single comparisons or ANOVA for multiple comparisons with appropriate post hoc testing. Sample sizes for all experiments were determined by power analyses based on previously published data.

\section{Results}

Inhibition of Drp1 attenuates mitochondrial fragmentation and dysfunction and ROS production in $\mathrm{A} \boldsymbol{\beta}$-treated neurons Recent studies have shown that excessive mitochondrial fragmentation contributes to $\mathrm{AD}$ pathogenesis via mitochondrial dysfunction (Cho et al., 2009; Wang et al., 2012a, 2012b; Park et al., 2014). To investigate the effect of mdivi-1, a Drp1 selective inhibitor, on A $\beta$-treated cells, SK/mito-YFP cells were incubated with $\mathrm{A} \beta$ (1-42) oligomer in the presence or absence of mdivi-1. According to the previous notions, treatment of $A \beta$ induced massive mitochondrial fragmentation. However, the $\mathrm{A} \beta$-mediated mitochondrial fission was highly blocked by treatment of mdivi-1 (Fig. $1 A-C)$. In addition, treatment of mdivi-1 significantly recovered $\mathrm{A} \beta$-mediated mitochondrial dysfunctions, including increased mitochondrial depolarization, ROS production, and decreased ATP levels, in SK-N-MC cells (Fig. $1 D-F$ ).

To further investigate the effect of mdivi- 1 on $\mathrm{A} \beta$-induced mitochondrial fission and dysfunction, primary cultured rat hippocampal neurons were exposed to $A \beta(1-42)$ oligomer with or without mdivi-1 and mitochondrial morphology was examined with a MitoTracker. Treatment of $\mathrm{A} \beta$ alone strongly increased 
A

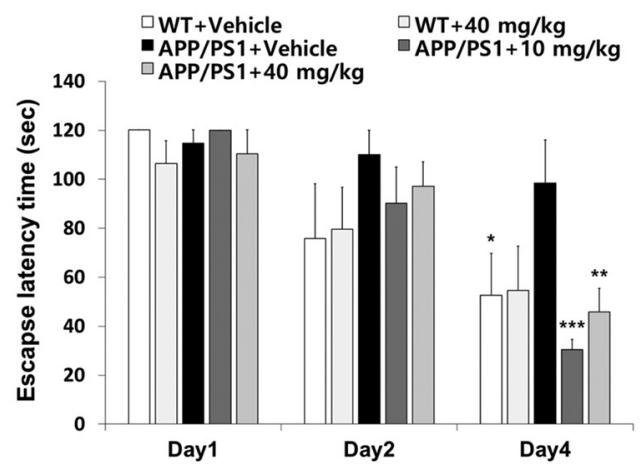

B

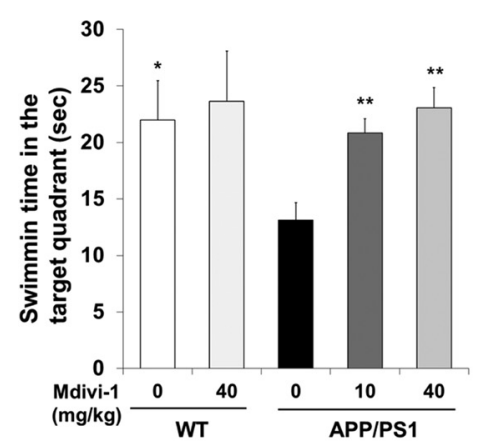

C

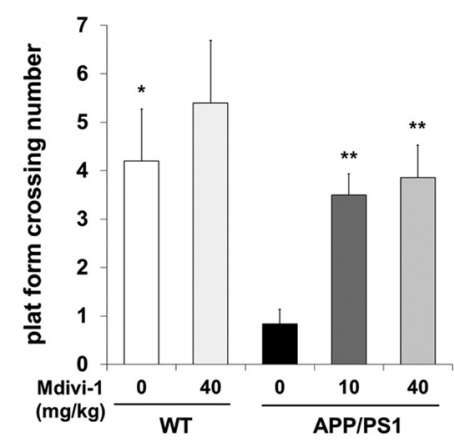

D
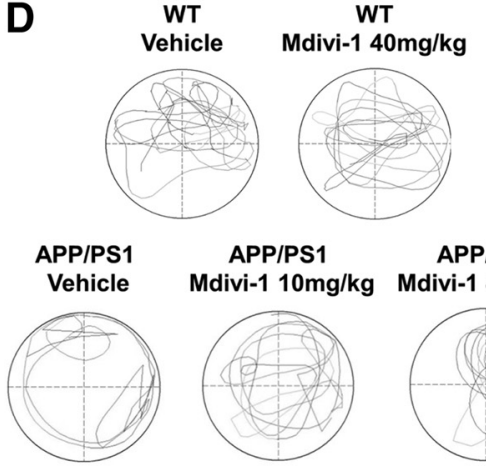

APP/PS1 Mdivi-1 10mg/kg Mdivi-140mg

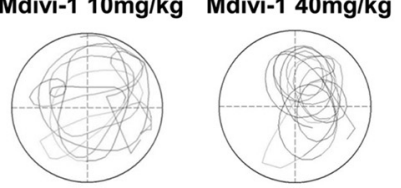

E

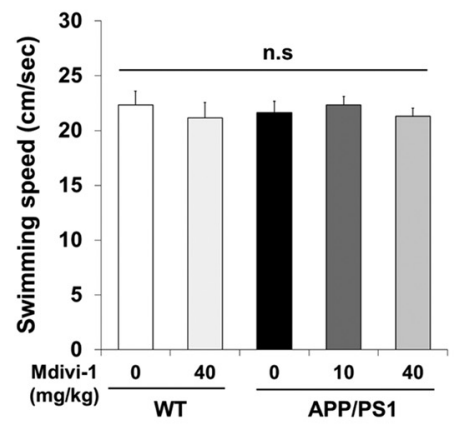

$\mathbf{F}$

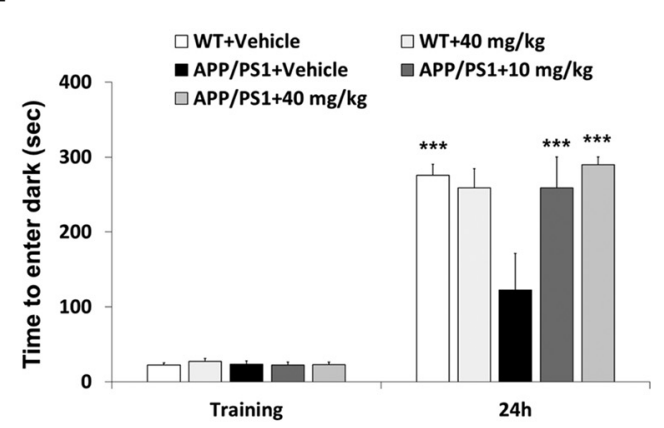

Figure 4. Treatment of mdivi-1 attenuates hippocampal memory impairment in APP/PS1 mice. APP/PS1 mice and age-matched WT littermates were administered with vehicle or mdivi-1 $(10 \mathrm{mg} / \mathrm{kg}, 40 \mathrm{mg} / \mathrm{kg})$ daily for 4 weeks. The effect of mdivi-1 on learning and memory in APP/PS1 mice versus vehicle-treated control mice by MWM test and passive avoidance test was determined. The average latency to escape to the hidden platform during each day of training sessions $(\boldsymbol{A})$, the time spent in the target quadrant where the hidden platform was previously placed during probe trial $(\boldsymbol{B})$, the mean number of mice crossing the target quadrant during probe trial $(\boldsymbol{C}$ ), typical swimming traces during probe test $(\boldsymbol{D})$, and visual swimming speed test $(\boldsymbol{E})$ of MWM test were performed. $\boldsymbol{F}$, Latency time in passive avoidance task was measured. Data represent means \pm SEM ( $n=7$ per group). One-way ANOVA followed by Bonferroni's post hoc comparisons tests were performed in statistical analyses $\left({ }^{*} p<0.05,{ }^{* *} p<0.01,{ }^{* * *} p<0.001\right.$ compared with the vehicle-treated control group).

mitochondrial fragmentation in hippocampal neurons, whereas cotreatment with mdivi-1 significantly reduced the $\mathrm{A} \beta$-mediated mitochondrial fission (Fig. $2 A, B$ ). Nonetheless, total mitochondrial intensity was not altered in $\mathrm{A} \beta$ or mdivi-1-treated cells, indicating that $\mathrm{A} \beta$ or mdivi-1 did not affect mitochondrial biogenesis (Fig. 2C). Next, we measured cellular ROS levels in response to $A \beta$ (1-42) oligomer and mdivi-1 by using the fluorescent probes $\mathrm{H}_{2}$ DCF-DA and MitoSox Red, which preferentially detect hydroxyl radical and mitochondrial superoxide, respectively. $\mathrm{A} \beta$-mediated intracellular ROS generation was suppressed by treatment of mdivi-1 in primary cultured hippocampal neurons (Fig. 2D). Treatment of mdivi-1 also caused a significant reduction of $\mathrm{A} \beta$-mediated mitochondrial superoxide generation (Fig. 2E). Together, these results suggest that inhibition of Drp1 using mdivi-1 attenuates $A \beta$-induced mitochondrial fragmentation, depolarization, and ROS accumulation in neurons.

\section{Inhibition of Drp 1 restores $A \boldsymbol{\beta}$-mediated synaptic depression} in hippocampal neurons

Next, we determined whether these morphological displacements are related to functional synaptic physiology at CNS synapses. To monitor synaptic vesicle exocytosis with high accuracy at nerve terminal, we used vGlut-pHluorin (vG-pH) expressed in primary cultured hippocampal neurons; PHluorin, a mutant form of GFP with fluorescence that can be quenched by protonation ( $\mathrm{pKa} \sim 7.1$ ) (Sankaranarayanan et al., 2000), is attached to the luminal region of synaptic vesicle transmembrane protein (vGlut1) and vG-pH is quenched in the resting state of synaptic vesicle which is in acidic condition ( $\sim p H$ 5.5). By actionpotential-driven synaptic vesicle exocytosis, it regains fluorescence with the alkaline extracellular environment. Neurons transfected with vG-pH were pretreated with DMSO (control), mdivi-1, $\mathrm{A} \beta$, and mdivi- 1 with $\mathrm{A} \beta$ for $3 \mathrm{~h}$. Subsequently, we measured vG-pH responses to 100 action potential stimuli at 10 $\mathrm{Hz}$ across boutons of neuron. Signal was normalized with entire synaptic vesicle pool by rapid application of $\mathrm{NH}_{4} \mathrm{Cl}$. Application of $\mathrm{A} \beta$ (1-42) oligomer resulted in $\sim 50 \%$ depression of exocytosis of synaptic vesicle, whereas vehicle (control) and mdivi-1treated neurons remained unchanged (Fig. 3). Synaptic depression by $\mathrm{A} \beta$ oligomers was significantly restored by treatment of mdivi-1, suggesting that $\mathrm{A} \beta$-induced mitochondria dysfunction causes impairment of functional synaptic physiology at CNS synapses and this disruption is restored by inhibition of mitochondrial fission by treatment with the Drp1 inhibitor mdivi-1.

\section{Inhibition of Drp1 improves learning and memory in APP/PS1 mice}

Because synaptic dysfunction mediated by $\mathrm{A} \beta$ causes molecular and cellular basis for cognitive deficits and neuropathological features in $\mathrm{AD}$, we next investigated the effect of Drp1 inhibition in learning and memory deficits using AD model mice, APP/PS1overexpressing Swedish APP (APP695swe) mutants, PS1 mutants (PS1-dE9), and age-matched WT littermates. We examined target searching strategy and the spatial reference memory using the MWM. This is the most common behavioral test used to determine hippocampal spatial memory deficits. The MWM latency period measured the time required for the animal to swim 
A

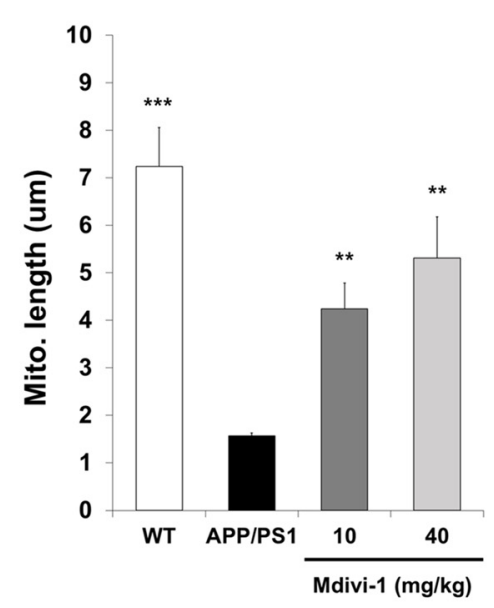

B

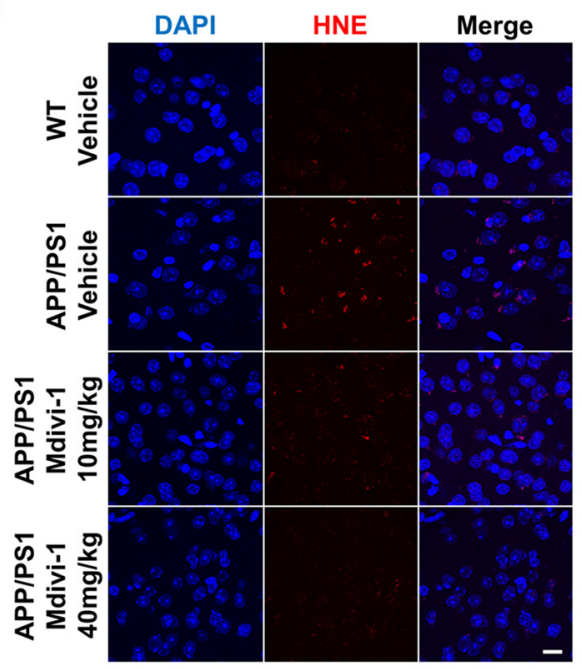

C

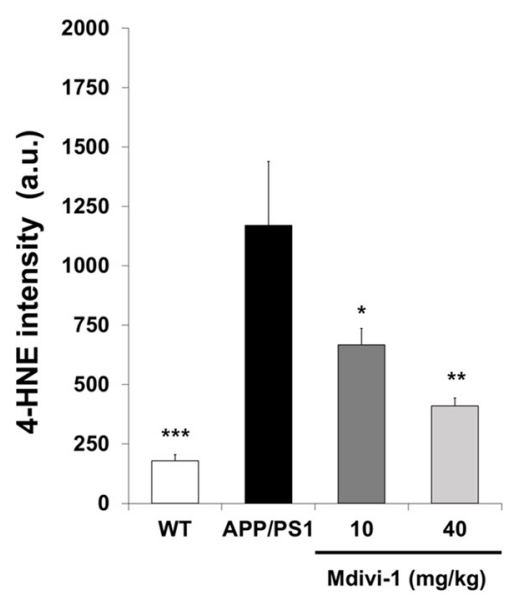

D

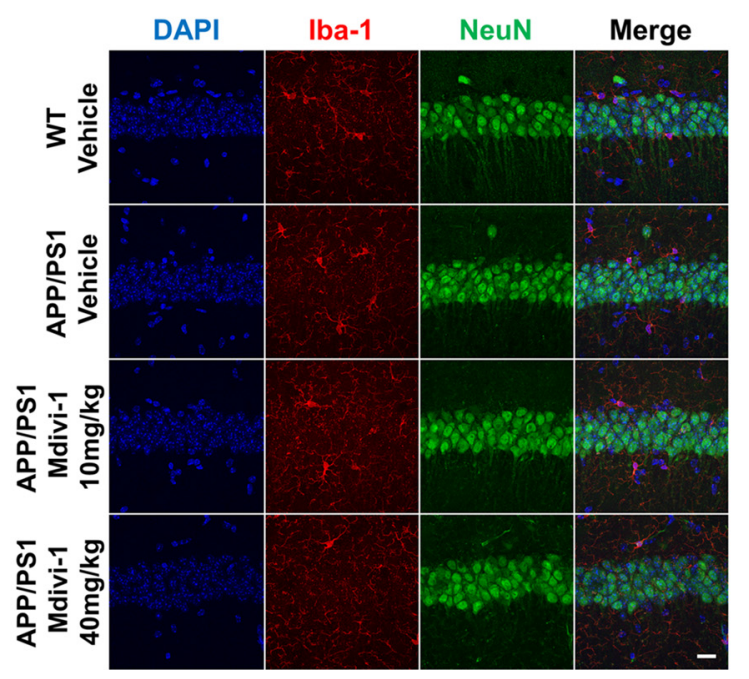

E

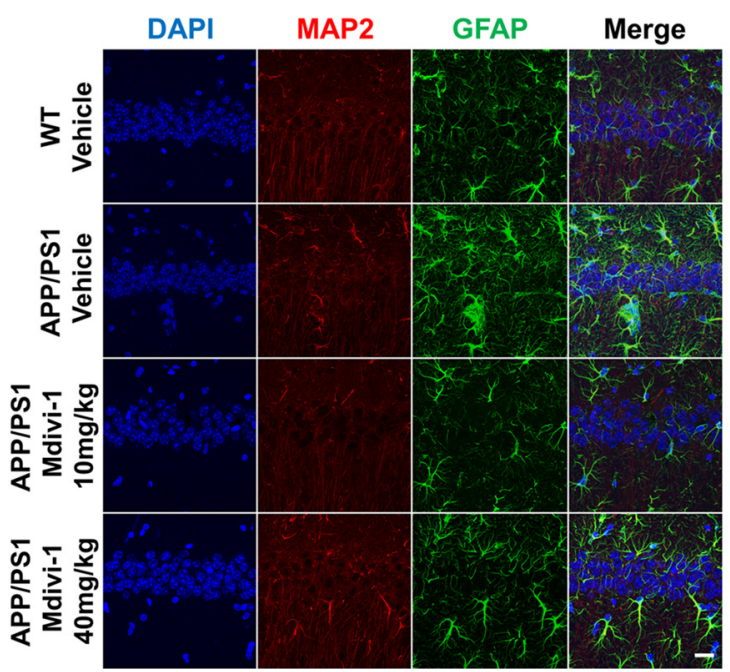

Figure 5. Administration of mdivi-1 reduces mitochondrial fragmentation and ROS production in the brain of APP/PS1 mice. A, APP/PS1 mice were administered with mdivi-1 (10 and $40 \mathrm{mg} / \mathrm{kg}$ ) daily for $38 \mathrm{~d}$ and control mice were give vehicle. After brain dissection, the tissues were stained with DAPI and MitoTracker for $20 \mathrm{~min}$. Then, the fluorescence images $(63 \times$ and zoom in $10 \times)$ were captured by a confocal microscopy and length of mitochondrial length was measured. B, C, APP/PS mice were administered with mdivi- $1(10 \mathrm{mg} / \mathrm{kg}, 40 \mathrm{mg} / \mathrm{kg})$ daily for $38 \mathrm{~d}$. After brain dissection, the tissues were stained with DAPI and anti-4-HNE antibody. Then, the fluorescence images $(40 \times)$ were captured by confocal microscopy $(\boldsymbol{B})$ and the fluorescence intensity of 4-HNE was measured (C). D, E, Brain sections of the indicated groups were stained with anti-lba-1 antibody, anti-NeuN antibody, anti-GFAP antibody, and anti-MAP2 antibody and immunohistochemical staining in hippocampus (CA1) was imaged with a confocal microscope. Scale bar, $20 \mu \mathrm{m}$. Data represent means \pm SEM ( $n=5$ per group). One-way ANOVA followed by Turkey posthoc comparisons tests were performed in all statistical analyses $\left({ }^{*} p<0.05,{ }^{* *} p<0.01,{ }^{* * *} p<0.001\right.$ vs the vehicle-treated control group).

to a submerged platform after being trained to learn the location of the platform, with shorter times reflecting improved memory. Compared with vehicle-treated APP/PS1 mice, mdivi-1-treated APP/PS1 mice revealed significantly shorter latency to find the hidden platform on day 4 of the training session (Fig. 4A). Moreover, in the probe test on the following day 5, mdivi-1-treated APP/PS1 mice showed an increased staying time in the target quadrant (Fig. $4 B$ ) and the number of times crossing the target after removing the platform than the vehicle-treated mice (Fig. $4 C, D)$. However, there was no considerable difference in the swimming speed among these groups (Fig. $4 E$ ), suggesting that the observed results in spatial learning and memory represent cognitive functions, but not altered motivation or motility of animals. We further assessed the effect of mdivi-1 on memory impairment with the passive avoidance test, a fear-motivated test to measure hippocampal-dependent associative learning of the animal. Performance in the passive avoidance test was assessed by the latency of entering the shock-paired dark compartment in the vehicle-administered APP/PS1 mice and mdivi-1-administered APP/PS1 mice groups. Compared with the vehicle-treated group, our data showed that the latency to enter the dark compartment in the mdivi-1-treated APP/PS1 group was significantly increased (Fig. 4F). However, mdivi-1 treatment on WT littermates did not improve learning and memory functions compared with the vehicle-treated control WT group.

mdivi-1 restores mitochondrial length and decreases ROS production and gliosis in APP/PS1 mice

Our findings showed that mdivi-1 inhibits ROS generation, mitochondrial fragmentation, and synaptic depression in $\mathrm{A} \beta$ treated cultured neurons (Figs. 1, 2, 3), as well as deficits of learning and memory of APP/PS1 mice (Fig. 4). We confirmed 
A

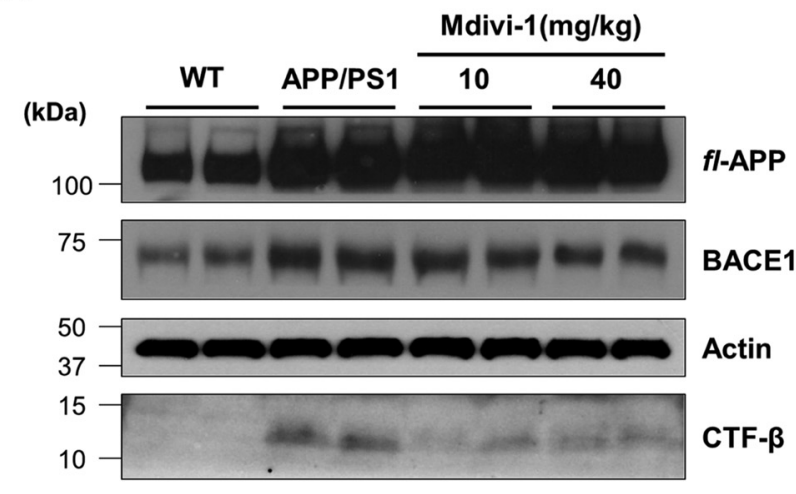

C

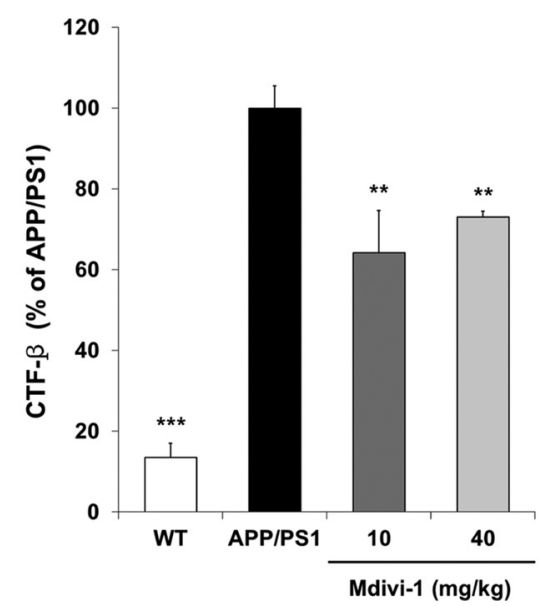

B

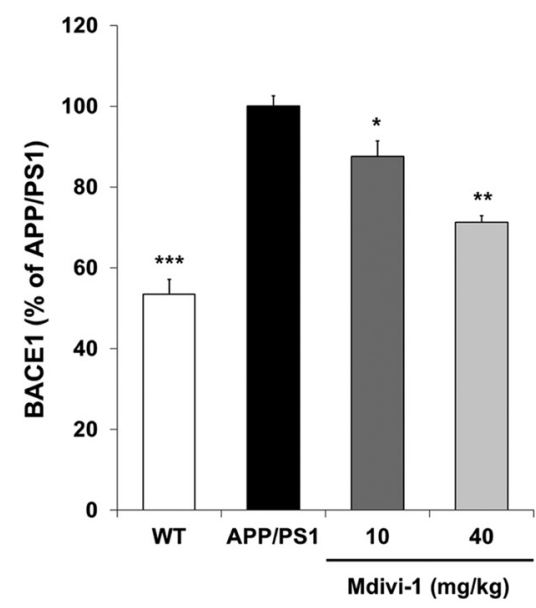

D

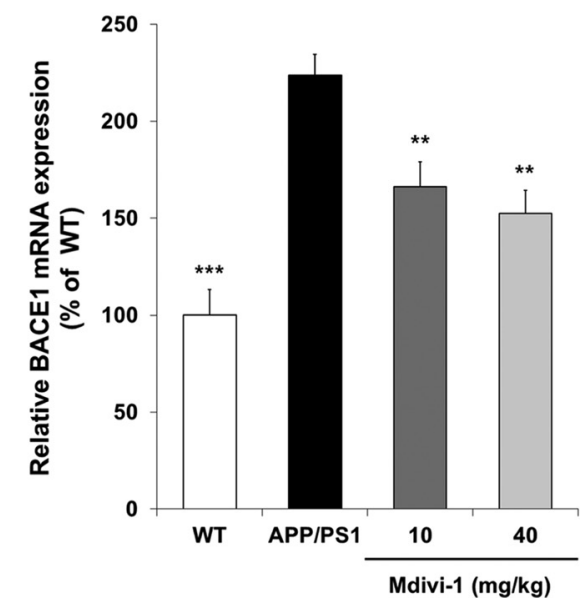

Figure 6. mdivi-1 reduces the expression of BACE1 and APP (TF- $\beta$ in the brain of APP/PS1 mice. APP/PS1 mice were administered with mdivi- 1 ( $10 \mathrm{mg} / \mathrm{kg}, 40 \mathrm{mg} / \mathrm{kg}$ ) daily for $38 \mathrm{~d}$. $A$, Expression of BACE1 and sAPP $\beta$ was examined by Western blot analysis with whole-brain protein extracts. $\boldsymbol{B}, \boldsymbol{C}$, optical density of BACE1 (B) and sAPP $\beta(\boldsymbol{C})$ protein by Western blotting was quantified with Image software. $D$, Expression level of BACE1 mRNA was determined by quantitative RT-PCR analysis with mRNA extracted from whole-brain tissues. Values are means \pm SEM ( $n=6$ per group). One-way ANOVA followed by Turkey post hoc comparisons tests were performed in all statistical analyses ( ${ }^{*} p<0.05,{ }^{* *} p<0.01,{ }^{* * *} p<0.001$ vs the vehicle-treated control group).

these observations in the brain tissues of midivi-1-administered APP/PS1 mice. To examine the mitochondrial length and the level of lipid peroxidation, the brain tissues were analyzed by immunohistochemistry with a MitoTracker and anti-4-HNEMichael adduct antibody. Quantitative analysis indicated that mitochondrial length is dramatically shortened in the APP/PS mice compared with age-matched WT littermates and the lipid peroxidation level is also highly increased in the brain tissue of APP/PS mice compared with WT mice (Fig. $5 A-C$ ). Treatment of mdivi-1 (40 mg/kg) notably elongates the mitochondrial length in the brain of APP/PS1 and WT mice compared with that of the vehicle-treated mice (Fig. $5 A$ ). Figure $5 B$ shows representative confocal microscopy images of 4-HNE-Michael adduct staining in the brain tissues of APP/PS1 mice. Treatment of mdivi-1 significantly reduced 4-HNE fluorescence intensity (Fig. 5C), suggesting that mdivi-1 inhibits mitochondrial fragmentation and lipid peroxidation in the brains of APP/PS1 mice. Next, we determined gliosis of APP/PS1 mice by staining for both activated microglia (Iba-1) and astrocytes (GFAP) (Fig. 5D,E). APP/PS1 mice showed the characteristic robust staining for both activated microglia (Iba-1) and astrocytes (GFAP). However, the mdivi-1treated APP/PS1 mice had significantly less immunoreactivity for Iba-1 and GFAP compared with vehicle-treated APP/PS1 mice.

mdivi-1 diminishes expression of BACE1 and decreases accumulation of $A \boldsymbol{\beta}$ plaques in APP/PS1 mice

It has been suggested previously that ROS positively contribute to $\mathrm{BACE} 1$ expression and generation of $\mathrm{A} \beta$. Therefore, we further investigated the effect of mdivi-1 on protein expression related to $\mathrm{A} \beta$ generation. APP/PS1 mice were administered with mdivi-1 for 4 weeks and the expression of BACE1 and APP CTF- $\beta$ were examined. BACE1 protein and mRNA and APP CTF- $\beta$ levels were significantly increased in APP/PS1 mice compared with WT mice (Fig. 6A-D). As shown in Figure 6, mice treated with mdivi-1 (40 mg/kg) showed significantly lower levels of both BACE1 and APP CTF- $\beta$ compared with the untreated control mice (Fig. $6 A-D$ ). However, the full-length APP protein level was not significantly affected by mdivi-1 treatments (Fig. $6 A$ ). The protein levels were calculated as a ratio against the loading control (Fig. $6 B, C$ ). These results implicate that mdivi-1 downregulates $A \beta$ generation by reducing ROS generation in the brain of APP/PS1 mice. Because a decreased level of BACE1 resulted in reduction of $\mathrm{A} \beta$, we investigated the effect of mdivi-1 on $\mathrm{A} \beta$ amyloidosis. Consistently, APP/PS1 mice administered with mdivi-1 showed significant reduction of accumulation of $\mathrm{A} \beta$ plaques in both hippocampus and cortex in the brain of APP/PS1 mice compared with that of control-treated mice (Fig. $7 A-C$ ).

No adverse effects observed in mdivi-1-treated APP/PS1 mice The body weights measured at the end of the dosing period were indistinguishable from those of vehicle-administered APP/PS1 mice or mdivi-1-treated APP/PS1 mice (Fig. $8 A$ ), which verified the toxicity of mdivi-1 in APP/PS1 mice. In addition, there were no differences in major organ weights among the study cohort, 
A

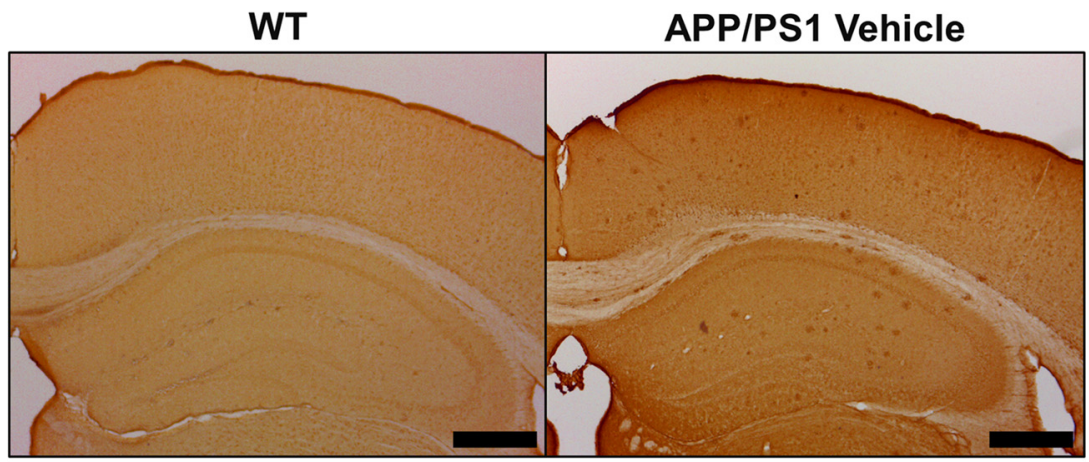

APP/PS1 Mdivi-1 10mg/kg APP/PS1 Mdivi-1 $40 \mathrm{mg} / \mathrm{kg}$

B

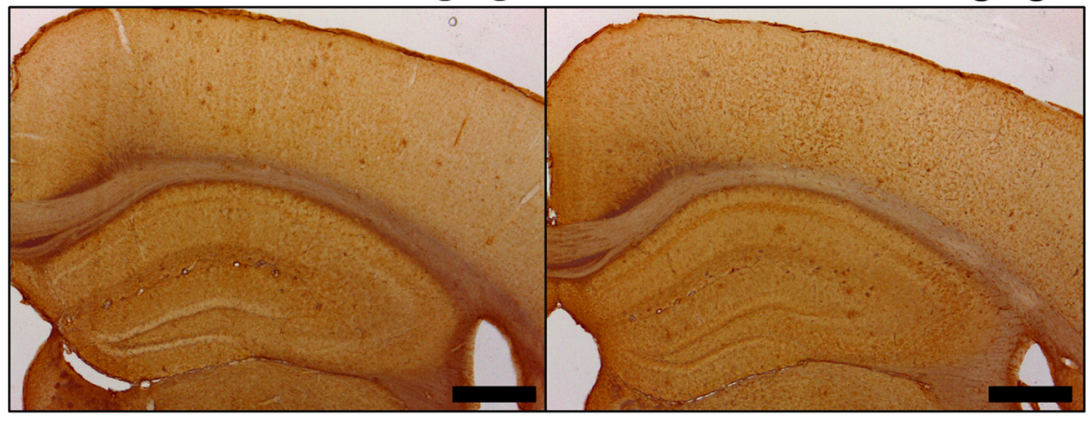

80

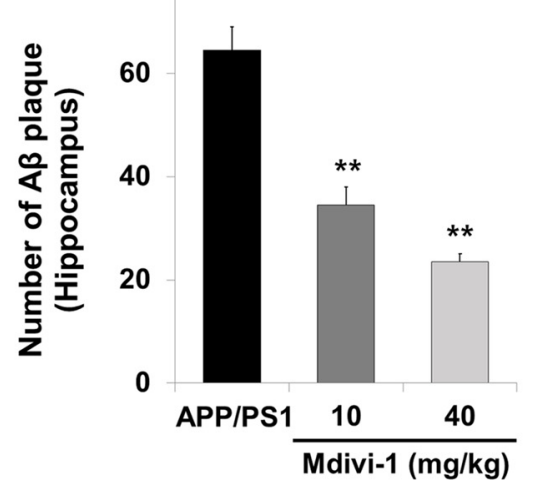

100

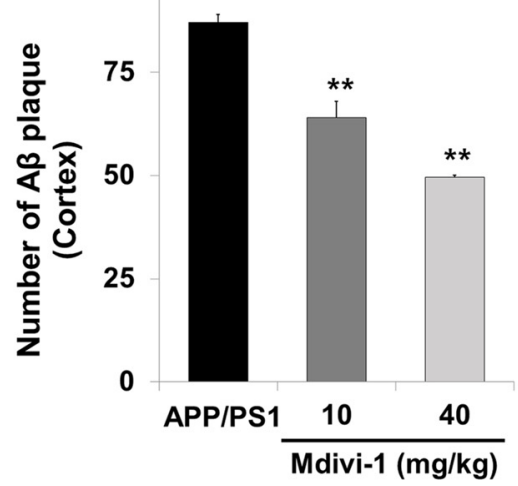

Figure 7. mdivi-1 reduces cerebral A $\beta$ load in the brain of APP/PS1 mice. APP/PS1 mice were administered with mdivi-1 (10 $\mathrm{mg} / \mathrm{kg}, 40 \mathrm{mg} / \mathrm{kg}$ ) daily for $38 \mathrm{~d}$. Brain sections from vehicle-treated or mdivi-1-treated APP/PS1 mice were incubated with an antibody against $A \beta(6 E 10)$ and visualized by DAB staining. The amyloid plaques in hippocampus and cortex were identified with microscopy $(\boldsymbol{A})$ and the neurite plaques in hippocampus $(\boldsymbol{B})$ and cortex $(\boldsymbol{C})$ were quantified. Scale bar, $800 \mu \mathrm{m}$. Values are means \pm SEM ( $n=5$ per group). One-way ANOVA followed by Turkey post hoc comparisons tests were performed in all statistical analyses $\left({ }^{* *} p<0.01\right)$.

including brain weight (Fig. $8 B$ ). This observation suggests that overt toxic effects of chronic mdivi-1 administration were not present in these animals.

\section{Discussion}

There is substantial evidence supporting that abnormal mitochondrial dynamics has a crucial role in pathogenesis of diverse neurodegenerative diseases, including $\mathrm{AD}, \mathrm{HD}, \mathrm{PD}$, and ALS (Haun et al., 2013a, 2013b; Mishra and Chan, 2014). In addition to $\mathrm{A} \beta$ depositions and neurofibrillary tau tangles, enhanced mitochondrial fission and synaptic loss are the important histopathological changes seen in the AD brain (Cho et al., 2009;
Reddy et al., 2012). Moreover, excessive mitochondrial fragmentation can contribute to $\mathrm{AD}$ pathogenesis through oxidative stress, synaptic damage, and neuronal death (Cho et al., 2009; Wang et al., 2014). Therefore, restoration of mitochondrial fission/fusion imbalance may have therapeutic value (Brooks et al., 2009; Liu et al., 2015). Nonetheless, it was not known whether inhibition of excessive fragmentation of mitochondria is advantageous in mammal models of $\mathrm{AD}$. In the present study, we determined the effect of Drp1 inhibition using mdivi- 1 on $\mathrm{A} \beta$-mediated mitochondrial dysfunction and $\mathrm{AD}$-associated neuropathology in cultured neurons and APP/PS1 double-transgenic AD mice. Our results illustrate that inhibition of Drp1 suppresses mitochondrial fission, mitochondrial depolarization, ROS production, and ATP reduction in $\mathrm{A} \beta$-treated neurons. Moreover, $\mathrm{A} \beta$-induced synaptic depression was significantly restored by inhibiting excessive mitochondria fragmentation with mdivi-1, a Drp1 inhibitor, which suggests that $A \beta$-mediated mitochondrial disruption causes impairment of functional synaptic physiology at neuronal synapses. Furthermore, mdivi-1 administration significantly reduced lipid peroxidation, BACE1 expression, $\mathrm{A} \beta$ deposition, and synaptic loss in the brain tissues of APP/PS1 mice. As a result, memory deficits in AD mice were rescued by Drp1 inhibition.

Increasing evidence has revealed that abnormalities in mitochondrial dynamics are early events in several neuronal diseases including AD (Wang et al., 2008, 2009b; Manczak et al., 2010, 2011; Calkins et al., 2011), HD (Wang et al., 2009a, 2009b; Costa et al., 2010; Song et al., 2011; Haun et al., 2013a, 2013b), PD (Kamp et al., 2010; Wang et al., 2012a, 2012b), ALS (Song et al., 2013), and multiple sclerosis (Kalman et al., 2003). In particular, abnormal mitochondrial dynamics and synaptic dysfunction, including $A \beta$ and hyperphosphorylated tau interaction with Drp1, increased mitochondrial fission, disturbed axonal transport, and synaptic degeneration, have been increasingly observed in neurons of $\mathrm{AD}$ patients and mouse models of $\mathrm{AD}$ with disease progression (Manczak et al., 2012). Progressively accumulated $\mathrm{A} \beta$ in mitochondria is associated with increased oxidative stress, reduced mitochondrial membrane potential and ATP production, disturbed mitochondrial calcium regulation, secretion of mitochondrial apoptotic factors, decreased mitochondrial motility, and increased mitochondrial fission (Lustbader et al., 2004; Yao et al., 2011; Cha et al., 2012). Although the precise molecular mechanism underlying excessive mitochondrial fragmentation in $\mathrm{AD}$ brain is not been well understood, several molecular mechanisms have been proposed. Reddy's group in- 
A

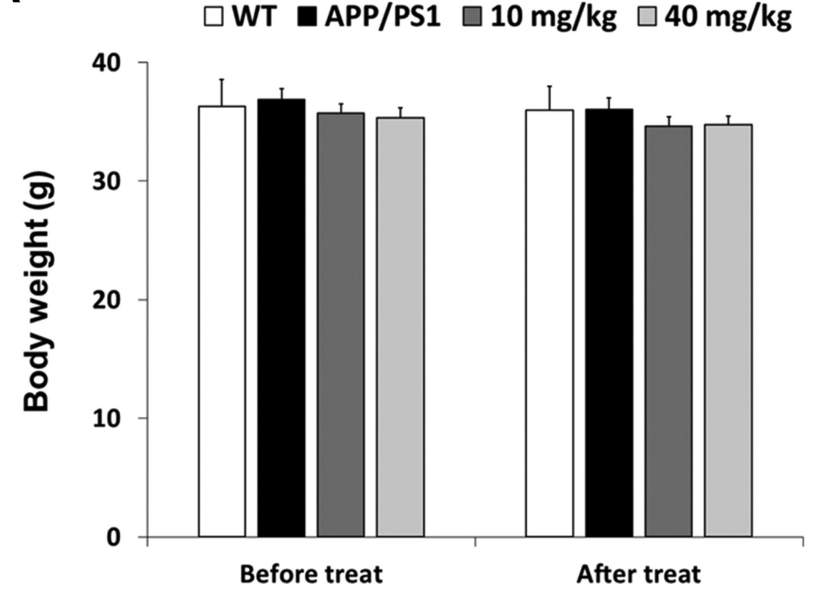

B

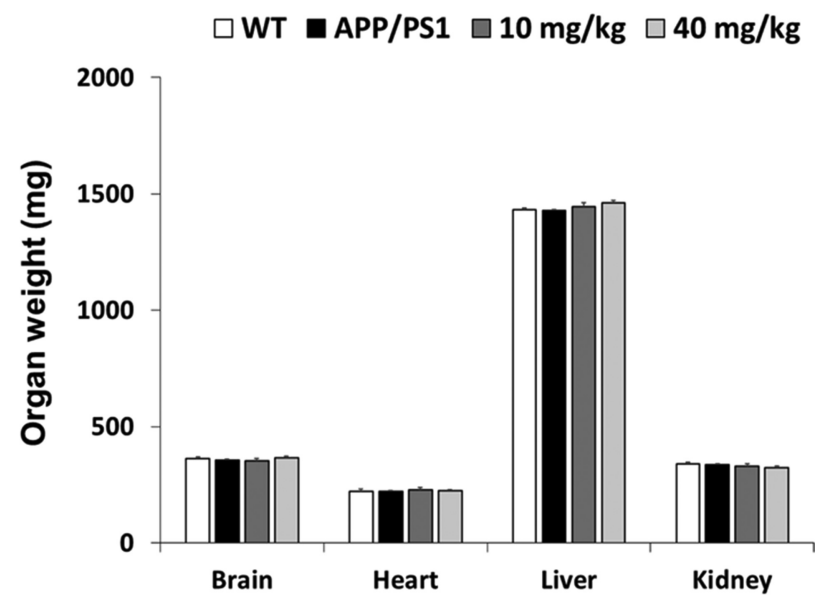

Figure 8. There was no adverse effect of chronic mdivi-1 treatment in APP/PS1 mice. To assess the toxicity of mdivi-1, APP/PS1 mice were given 0, 10 , or $40 \mathrm{mg} / \mathrm{kg} / \mathrm{d}$ mdivi-1 orally for $40 \mathrm{~d}$. mdivi-1-administered or vehicle-treated male mice from 7 months of age were assessed for final body weights and organs weights. $A$, Body weights measured at the end of the dosing period were indistinguishable from vehicle-administered APP/PS1 mice or mdivi-1-treated APP/PS1 mice, which verified the toxicity of mdivi-1 in APP/PS1 mice. $\boldsymbol{B}$, In addition, there were no differences in major organ weights among the study cohort, including brain weight. There was no statistically significant change among any of the group within the measures as determined by one-way ANOVA with Tukey's post hoc analysis.

vestigated the interaction of Drp1 with $A \beta$ and phosphorylated tau and Drp1 GTPase activity in the brain specimens from AD patients and AD mice (Manczak et al., 2011; Manczak et al., 2012). Their study showed a progressively increased interaction among Drp1, $A \beta$, and phosphorylated tau, which enhanced GTPase enzymatic activity of Drpl and resulted in excessive mitochondrial fragmentation. Furthermore, it was revealed that S-nitrosylation of Drp1 at Cys644 caused mitochondrial fragmentation in brain neurons from $\mathrm{AD}$ and $\mathrm{HD}$ patients (Cho et al., 2009; Haun et al., 2013a, 2013b). Cys644 residue resides within the GTPase effector domain of Drp1, which affects both oligomer formation and GTPase activity of Drp1 (Zhu et al., 2004; Cho et al., 2009). S-nitrosylation of Drp1 induces its dimerization and activates its GTPase activity; however, mutation of Cys644 to Ala (C664A) abrogates these effects of NO (Cho et al., 2009). Moreover, blocking of Drp1 S-nitrosylation using C664A mutant prevented $\mathrm{A} \beta$-mediated mitochondrial fission, synaptic damage, and neuronal death. These findings suggest that A $\beta$ enhances Drp1 activity and causes excessive mitochondrial fission, leading to mitochondrial dysfunction and neuronal death in $\mathrm{AD}$ progression. Findings from these studies also suggest that inhibitors of mitochondrial fission could be potential therapeutic targets for reducing Drp1 GTPase activity in patients with AD. Consistently, we observed that inhibition of Drp1 GTPase activity prevented $\mathrm{A} \beta$-mediated mitochondrial fission, mitochondrial depolarization, ROS production, and ATP reduction in cultured neurons.

Mitochondria residing at synapses are usually older and are therefore much more vulnerable to cumulative damage mediated by deleterious factors such as $\mathrm{A} \beta$ compared with nonsynaptic mitochondria (Du et al., 2010). Moreover, early deposition of A $\beta$ occurs in mitochondria residing in synapses, which might make synaptic mitochondria much more vulnerable to $\mathrm{A} \beta$ toxicity (Dragicevic et al., 2010; Du et al., 2010). Accordingly, synaptic mitochondria are functionally compromised and show greater vulnerability to damage compared with nonsynaptic mitochondria in AD mice (Dragicevic et al., 2010; Du et al., 2010). These observations indicate that dysfunction of synaptic mitochondria occurs early in the progress of $\mathrm{AD}$ and disturbance of synaptic mitochondria plays a key role in $\mathrm{A} \beta$-mediated mitochondrial and neurosynaptic toxicity. Therefore, we determined whether inhibition of mitochondrial fission would be beneficial for $\mathrm{A} \beta$ mediated synaptic dysfunction. Treatment of $A \beta$ oligomers induced significant depression of exocytosis of synaptic vesicle; however, mdivi-1-treated neurons showed normal synaptic exocytosis. $\mathrm{A} \beta$ oligomers-mediated synaptic depression was significantly protected by application of mdivi- 1 , indicating that $\mathrm{A} \beta$-induced mitochondria dysfunction causes impairment of functional synaptic physiology. Therefore, we first proved that $\mathrm{A} \beta$ oligomermediated functional synaptic failure was through excessive mitochondrial fission.

mdivi-1, a derivative of quinazolinone, has been identified as a cell-permeable selective inhibitor of Drp1 (Cassidy-Stone et al., 2008). mdivi-1 inhibits GTPase activity by blocking the selfassembly of Drp1 and mitochondrial fission. The mdivi-1 molecule has been investigated in several experimental animal models for seizures (Xie et al., 2013a, 2013b), epilepsy (Qiu et al., 2013), cerebral ischemia/reperfusion (Zhang et al., 2013; Liu et al., 2015), rhabdomyolysis (Tang et al., 2013), HD (Manczak and Reddy, 2015), and diabetes (Huang et al., 2015). Another Drp1 inhibitor, P110, has been studied in an HD animal model (Guo et al., 2013). The Drp1 inhibitors exhibited protective effects on affected cells and tissues by ameliorating excessive mitochondrial fragmentation and maintaining the normal mitochondrial functions in all of these investigated animal models of diseases. However, it was not clear whether mdivi-1 ameliorates neuropathology and memory decline by improved neuropathology in AD mice models. In this study, we exploited APP/PS1 doubletransgenic mice overexpressing both an APP695swe mutant and a PS1 mutant (PS1-dE9), which are highly associated with earlyonset $\mathrm{AD}$. APP/PS1 mice showed progressively increased $\mathrm{A} \beta$ deposition, modest neuron loss, dendritic spin loss, and cognitive deficits in spatial learning and memory (Radde et al., 2006; Serneels et al., 2009; Rupp et al., 2011; Bittner et al., 2012). We found that the administration of mdivi-1 could improve learning and memory performance in APP/PS1 mice, suggesting that Drp1mediated mitochondria fragmentation is required for impairment of learning and memory in the APP/PS1-transgenic mice. Expectedly, we also observed reduced lipid peroxidation and mitochondrial fission in the brain tissues of midivi-1-administered 
APP/PS1 mice. Previous studies reported that oxidative stress is known to be associated with increased BACE1 expression, $\gamma$-secretase activity, and A $\beta$ (Tamagno et al., 2002; Jo et al., 2010; Gwon et al., 2012). Therefore, excessive mitochondrial fissionmediated mitochondrial oxidative stress could be an upstream regulator of BACE1 expression, APP processing, and amyloid pathology, resulting in declined learning and memory in $\mathrm{AD}$. Notably, we had determined that inhibition of Drp1 activity by mdivi- 1 attenuated both BACE1 expression and accumulation of $\mathrm{A} \beta$, as well as memory decline in APP/PS1 mice, which suggested that inhibition of excessive mitochondrial fragmentation might have important roles in alleviating $\mathrm{A} \beta$ production and deposition in $\mathrm{AD}$. Despite these results, the role of Drp1 in mdivi-1mediated amelioration of pathogenesis of Alzheimer's disease is further elucidated.

Together, our studies in $\mathrm{A} \beta$-treated neurons and in vivo animal model of AD suggest that neuropathology and combined cognitive decline can be attributed, at least in part, to hyperactivation of Drp1 in the pathogenesis of AD. Our data further indicate that inhibitors of excessive mitochondrial fission, such as Drpl inhibitors, may be effective strategies for preventing and halting the progression of $\mathrm{AD}$.

\section{References}

Baik SH et al. (2015) Pinl promotes neuronal death in stroke by stabilizing Notch intracellular domain. Ann Neurol 77:504-516. CrossRef Medline

Baloyannis SJ (2006) Mitochondrial alterations in Alzheimer's disease. J Alzheimers Dis 9:119-126. CrossRef Medline

Bittner T, Burgold S, Dorostkar MM, Fuhrmann M, Wegenast-Braun BM, Schmidt B, Kretzschmar H, Herms J (2012) Amyloid plaque formation precedes dendritic spine loss. Acta Neuropathol 124:797-807. CrossRef Medline

Brooks C, Wei Q, Cho SG, Dong Z (2009) Regulation of mitochondrial dynamics in acute kidney injury in cell culture and rodent models. J Clin Invest 119:1275-1285. CrossRef Medline

Calkins MJ, Manczak M, Mao P, Shirendeb U, Reddy PH (2011) Impaired mitochondrial biogenesis, defective axonal transport of mitochondria, abnormal mitochondrial dynamics and synaptic degeneration in a mouse model of Alzheimer's disease. Hum Mol Genet 20:4515-4529. CrossRef Medline

Cassidy-Stone A, Chipuk JE, Ingerman E, Song C, Yoo C, Kuwana T, Kurth MJ, Shaw JT, Hinshaw JE, Green DR, Nunnari J (2008) Chemical inhibition of the mitochondrial division dynamin reveals its role in Bax/Bakdependent mitochondrial outer membrane permeabilization. Dev Cell 14:193-204. CrossRef Medline

Cha MY, Han SH, Son SM, Hong HS, Choi YJ, Byun J, Mook-Jung I (2012) Mitochondria-specific accumulation of amyloid $\beta$ induces mitochondrial dysfunction leading to apoptotic cell death. PLoS One 7:e34929. CrossRef Medline

Cho B, Choi SY, Cho HM, Kim HJ, Sun W (2013) Physiological and pathological significance of dynamin-related protein 1 (drp1)-dependent mitochondrial fission in the nervous system. Exp Neurobiol 22:149-157. CrossRef Medline

Cho DH, Nakamura T, Fang J, Cieplak P, Godzik A, Gu Z, Lipton SA (2009) S-nitrosylation of Drp1 mediates beta-amyloid-related mitochondrial fission and neuronal injury. Science 324:102-105. CrossRef Medline

Cho DH, Nakamura T, Lipton SA (2010) Mitochondrial dynamics in cell death and neurodegeneration. Cell Mol Life Sci 67:3435-3447. CrossRef Medline

Costa V, Giacomello M, Hudec R, Lopreiato R, Ermak G, Lim D, Malorni W, Davies KJ, Carafoli E, Scorrano L (2010) Mitochondrial fission and cristae disruption increase the response of cell models of Huntington's disease to apoptotic stimuli. EMBO Mol Med 2:490-503. CrossRef Medline

Dragicevic N, Mamcarz M, Zhu Y, Buzzeo R, Tan J, Arendash GW, Bradshaw PC (2010) Mitochondrial amyloid-beta levels are associated with the extent of mitochondrial dysfunction in different brain regions and the degree of cognitive impairment in Alzheimer's transgenic mice. J Alzheimers Dis 20:S535-S550. CrossRef Medline

Du H, Guo L, Yan S, Sosunov AA, McKhann GM, Yan SS (2010) Early deficits in synaptic mitochondria in an Alzheimer's disease mouse model. Proc Natl Acad Sci U S A 107:18670-18675. CrossRef Medline

DuBoff B, Feany M, Götz J (2013) Why size matters-balancing mitochondrial dynamics in Alzheimer's disease. Trends Neurosci 36:325-335. CrossRef Medline

Granseth B, Odermatt B, Royle SJ, Lagnado L (2006) Clathrin-mediated endocytosis is the dominant mechanism of vesicle retrieval at hippocampal synapses. Neuron 51:773-786. CrossRef Medline

Guo X, Disatnik MH, Monbureau M, Shamloo M, Mochly-Rosen D, Qi X (2013) Inhibition of mitochondrial fragmentation diminishes Huntington's disease-associated neurodegeneration. J Clin Invest 123:5371-5388. CrossRef Medline

Gwon AR, Park JS, Arumugam TV, Kwon YK, Chan SL, Kim SH, Baik SH, Yang S, Yun YK, Choi Y, Kim S, Tang SC, Hyun DH, Cheng A, Dann CE 3rd, Bernier M, Lee J, Markesbery WR, Mattson MP, Jo DG (2012) Oxidative lipid modification of nicastrin enhances amyloidogenic $\gamma$-secretase activity in Alzheimer's disease. Aging Cell 11:559-568. CrossRef Medline

Haun F, Nakamura T, Lipton SA (2013a) Dysfunctional mitochondrial dynamics in the pathophysiology of neurodegenerative diseases. J Cell Death 6:27-35. Medline

Haun F, Nakamura T, Shiu AD, Cho DH, Tsunemi T, Holland EA, La Spada AR, Lipton SA (2013b) S-nitrosylation of dynamin-related protein 1 mediates mutant huntingtin-induced mitochondrial fragmentation and neuronal injury in Huntington's disease. Antioxid Redox Signal 19:11731184. CrossRef Medline

Huang S, Wang Y, Gan X, Fang D, Zhong C, Wu L, Hu G, Sosunov AA, McKhann GM, Yu H, Yan SS (2015) Drp1-mediated mitochondrial abnormalities link to synaptic injury in diabetes model. Diabetes 64:1728 1742. CrossRef Medline

Itoh K, Nakamura K, Iijima M, Sesaki H (2013) Mitochondrial dynamics in neurodegeneration. Trends Cell Biol 23:64-71. CrossRef Medline

Jo DG, Arumugam TV, Woo HN, Park JS, Tang SC, Mughal M, Hyun DH, Park JH, Choi YH, Gwon AR, Camandola S, Cheng A, Cai H, Song W, Markesbery WR, Mattson MP (2010) Evidence that gamma-secretase mediates oxidative stress-induced beta-secretase expression in Alzheimer's disease. Neurobiol Aging 31:917-925. CrossRef Medline

Kalman B, Leist TP (2003) A mitochondrial component of neurodegeneration in multiple sclerosis. Neuromolecular Med 3:147-158. CrossRef Medline

Kamp F, Exner N, Lutz AK, Wender N, Hegermann J, Brunner B, Nuscher B, Bartels T, Giese A, Beyer K, Eimer S, Winklhofer KF, Haass C (2010) Inhibition of mitochondrial fusion by $\alpha$-synuclein is rescued by PINK1, Parkin and DJ-1. EMBO J 29:3571-3589. CrossRef Medline

Kim SH, Ryan TA (2009) Synaptic vesicle recycling at CNS snapses without AP-2. J Neurosci 29:3865-3874. CrossRef Medline

Lee YJ, Jeong SY, Karbowski M, Smith CL, Youle RJ (2004) Roles of the mammalian mitochondrial fission and fusion mediators Fis1, Drp1, and Opal in apoptosis. Mol Biol Cell 15:5001-5011. CrossRef Medline

Liu JM, Yi Z, Liu SZ, Chang JH, Dang XB, Li QY, Zhang YL (2015) The mitochondrial division inhibitor mdivi-1 attenuates spinal cord ischemiareperfusion injury both in vitro and in vivo: Involvement of BK channels. Brain Res 1619:155-165. CrossRef Medline

Lustbader JW et al. (2004) ABAD directly links Abeta to mitochondrial toxicity in Alzheimer's disease. Science 304:448-452. CrossRef Medline

Manczak M, Reddy PH (2012) Abnormal interaction between the mitochondrial fission protein Drp1 and hyperphosphorylated tau in Alzheimer's disease neurons: implications for mitochondrial dysfunction and neuronal damage. Hum Mol Genet 21:2538-2547. CrossRef Medline

Manczak M, Reddy PH (2015) Mitochondrial division inhibitor 1 protects against mutant huntingtin-induced abnormal mitochondrial dynamics and neuronal damage in Huntington's disease. Hum Mol Genet 24:7308 7325. CrossRef Medline

Manczak M, Mao P, Calkins MJ, Cornea A, Reddy AP, Murphy MP, Szeto HH, Park B, Reddy PH (2010) Mitochondria-targeted antioxidants protect against amyloid-beta toxicity in Alzheimer's disease neurons. J Alzheimers Dis 20:S609-S631. CrossRef Medline

Manczak M, Calkins MJ, Reddy PH (2011) Impaired mitochondrial dynamics and abnormal interaction of amyloid beta with mitochondrial protein Drp1 in neurons from patients with Alzheimer's disease: implications for neuronal damage. Hum Mol Genet 20:2495-2509. CrossRef Medline

Mishra P, Chan DC (2014) Mitochondrial dynamics and inheritance during 
cell division, development and disease. Nat Rev Mol Cell Biol 15:634646. CrossRef Medline

Otera H, Wang C, Cleland MM, Setoguchi K, Yokota S, Youle RJ, Mihara K (2010) Mff is an essential factor for mitochondrial recruitment of Drp1 during mitochondrial fission in mammalian cells. J Cell Biol 191:11411158. CrossRef Medline

Park SJ, Shin JH, Jeong JI, Song JH, Jo YK, Kim ES, Lee EH, Hwang JJ, Lee EK, Chung SJ, Koh JY, Jo DG, Cho DH (2014) Down-regulation of mortalin exacerbates $\mathrm{A} \beta$-mediated mitochondrial fragmentation and dysfunction. J Biol Chem 289:2195-2204. CrossRef Medline

Qiu X, Cao L, Yang X, Zhao X, Liu X, Han Y, Xue Y, Jiang H, Chi Z (2013) Role of mitochondrial fission in neuronal injury in pilocarpine-induced epileptic rats. Neuroscience 245:157-165. CrossRef Medline

Radde R, Bolmont T, Kaeser SA, Coomaraswamy J, Lindau D, Stoltze L, Calhoun ME, Jäggi F, Wolburg H, Gengler S, Haass C, Ghetti B, Czech C, Hölscher C, Mathews PM, Jucker M (2006) Abeta42-driven cerebral amyloidosis in transgenic mice reveals early and robust pathology. EMBO Rep 7:940-946. CrossRef Medline

Reddy PH (2014) Inhibitors of mitochondrial fission as a therapeutic strategy for diseases with oxidative stress and mitochondrial dysfunction. J Alzheimers Dis 40:245-256. CrossRef Medline

Reddy PH, Tripathi R, Troung Q, Tirumala K, Reddy TP, Anekonda V, Shirendeb UP, Calkins MJ, Reddy AP, Mao P, Manczak M (2012) Abnormal mitochondrial dynamics and synaptic degeneration as early events in Alzheimer's disease: implications to mitochondria-targeted antioxidant therapeutics. Biochim Biophys Acta 1822:639-649. CrossRef Medline

Rupp NJ, Wegenast-Braun BM, Radde R, Calhoun ME, Jucker M (2011) Early onset amyloid lesions lead to severe neuritic abnormalities and local, but not global neuron loss in APPPS1 transgenic mice. Neurobiol Aging 32:2324 e1-e6. CrossRef Medline

Sankaranarayanan S, Ryan TA (2000) Real-time measurements of vesicleSNARE recycling in synapses of the central nervous system. Nat Cell Biol 2:197-204. CrossRef Medline

Sankaranarayanan S, De Angelis D, Rothman JE, Ryan TA (2000) The use of pHluorins for optical measurements of presynaptic activity. Biophys J 79:2199-2208. CrossRef Medline

Serneels L, et al. (2009) gamma-Secretase heterogeneity in the Aphl subunit: relevance for Alzheimer's disease. Science 324:639-642. CrossRef Medline

Song W, Chen J, Petrilli A, Liot G, Klinglmayr E, Zhou Y, Poquiz P, Tjong J, Pouladi MA, Hayden MR, Masliah E, Ellisman M, Rouiller I, Schwarzenbacher R, Bossy B, Perkins G, Bossy-Wetzel E (2011) Mutant huntingtin binds the mitochondrial fission GTPase dynamin-related protein- 1 and increases its enzymatic activity. Nat Med 17:377-382. CrossRef Medline

Song W, Song Y, Kincaid B, Bossy B, Bossy-Wetzel E (2013) Mutant SOD1G93A triggers mitochondrial fragmentation in spinal cord motor neurons: neuroprotection by SIRT3 and PGC- $1 \alpha$. Neurobiol Dis 51:7281. CrossRef Medline

Tamagno E, Bardini P, Obbili A, Vitali A, Borghi R, Zaccheo D, Pronzato MA, Danni O, Smith MA, Perry G, Tabaton M (2002) Oxidative stress in- creases expression and activity of BACE in NT2 neurons. Neurobiol Dis 10:279-288. CrossRef Medline

Tang WX, Wu WH, Qiu HY, Bo H, Huang SM (2013) Amelioration of rhabdomyolysis-induced renal mitochondrial injury and apoptosis through suppression of Drp-1 translocation. J Nephrol 26:1073-1082. CrossRef Medline

Tu S, Okamoto S, Lipton SA, Xu H (2014) Oligomeric A $\beta$-induced synaptic dysfunction in Alzheimer's disease. Mol Neurodegener 9:48. CrossRef Medline

Wang H, Lim PJ, Karbowski M, Monteiro MJ (2009a) Effects of overexpression of huntingtin proteins on mitochondrial integrity. Hum Mol Genet 18:737-752. CrossRef Medline

Wang S, Song J, Tan M, Albers KM, Jia J (2012a) Mitochondrial fission proteins in peripheral blood lymphocytes are potential biomarkers for Alzheimer's disease. Eur J Neurol 19:1015-1022. CrossRef Medline

Wang X, Su B, Siedlak SL, Moreira PI, Fujioka H, Wang Y, Casadesus G, Zhu X (2008) Amyloid-beta overproduction causes abnormal mitochondrial dynamics via differential modulation of mitochondrial fission/fusion proteins. Proc Natl Acad Sci U S A 105:19318-19323. CrossRef Medline

Wang X, Su B, Lee HG, Li X, Perry G, Smith MA, Zhu X (2009b) Impaired balance of mitochondrial fission and fusion in Alzheimer's disease. J Neurosci 29:9090-9103. CrossRef Medline

Wang X, Petrie TG, Liu Y, Liu J, Fujioka H, Zhu X (2012b) Parkinson's disease-associated DJ-1 mutations impair mitochondrial dynamics and cause mitochondrial dysfunction. J Neurochem 121:830-839. CrossRef Medline

Wang X, Wang W, Li L, Perry G, Lee HG, Zhu X (2014) Oxidative stress and mitochondrial dysfunction in Alzheimer's disease. Biochim Biophys Acta 1842:1240-1247. CrossRef Medline

Xie H, Guan J, Borrelli LA, Xu J, Serrano-Pozo A, Bacskai BJ (2013a) Mitochondrial alterations near amyloid plaques in an Alzheimer's disease mouse model. J Neurosci 33:17042-17051. CrossRef Medline

Xie N, Wang C, Lian Y, Zhang H, Wu C, Zhang Q (2013b) A selective inhibitor of Drp1, mdivi-1, protects against cell death of hippocampal neurons in pilocarpine-induced seizures in rats. Neurosci Lett 545: 64-68. CrossRef Medline

Yao J, Du H, Yan S, Fang F, Wang C, Lue LF, Guo L, Chen D, Stern DM, Gunn Moore FJ, Xi Chen J, Arancio O, Yan SS (2011) Inhibition of amyloidbeta (Abeta) peptide-binding alcohol dehydrogenase-Abeta interaction reduces Abeta accumulation and improves mitochondrial function in a mouse model of Alzheimer's disease. J Neurosci 31:2313-2320. CrossRef Medline

Zhang N, Wang S, Li Y, Che L, Zhao Q (2013) A selective inhibitor of Drp1, mdivi-1, acts against cerebral ischemia/reperfusion injury via an antiapoptotic pathway in rats. Neurosci Lett 535:104-109. CrossRef Medline

Zhu PP, Patterson A, Stadler J, Seeburg DP, Sheng M, Blackstone C (2004) Intra- and intermolecular domain interactions of the C-terminal GTPase effector domain of the multimeric dynamin-like GTPase Drp1. J Biol Chem 279:35967-35974. CrossRef Medline 